\title{
A Critical Review of Unmanned Aerial Vehicles (UAVs) Use in Architecture and Urbanism: Scientometric and Bibliometric Analysis
}

\author{
Marta Videras Rodríguez ${ }^{1}\left(\mathbb{D}\right.$, Sergio Gómez Melgar $\left.{ }^{2, *} \mathbb{(}\right)$, Antonio Sánchez Cordero ${ }^{1}(\mathbb{D}$ and \\ José Manuel Andújar Márquez ${ }^{2} \mathbb{B}$ \\ 1 Programa de Doctorado de Ciencia y Tecnología Industrial y Ambiental, Centro de Investigación en \\ Tecnología, Energía y Sostenibilidad-CITES, Campus El Carmen, Universidad de Huelva, \\ 21071 Huelva, Spain; marta.videras245@alu.uhu.es (M.V.R.); antonio.sanchez443@alu.uhu.es (A.S.C.) \\ 2 TEP192 Control y Robótica, Centro de Investigación en Tecnología, Energía y Sostenibilidad-CITES, \\ Campus El Carmen, Universidad de Huelva, 21071 Huelva, Spain; andujar@uhu.es \\ * Correspondence: sergomel@uhu.es
}

Citation: Videras Rodríguez, M.; Melgar, S.G.; Cordero, A.S.; Márquez, J.M.A. A Critical Review of Unmanned Aerial Vehicles (UAVs) Use in Architecture and Urbanism: Scientometric and Bibliometric Analysis. Appl. Sci. 2021, 11, 9966. https://doi.org/10.3390/app11219966

Academic Editor: Paolo Visconti

Received: 27 September 2021

Accepted: 21 October 2021

Published: 25 October 2021

Publisher's Note: MDPI stays neutral with regard to jurisdictional claims in published maps and institutional affiliations.

Copyright: (c) 2021 by the authors. Licensee MDPI, Basel, Switzerland. This article is an open access article distributed under the terms and conditions of the Creative Commons Attribution (CC BY) license (https:// creativecommons.org/licenses/by/ $4.0 /)$.

\begin{abstract}
In recent years the use of UAVs (Unmanned aerial vehicles) have proliferated in the civil sector for purposes such as search and rescue, remote sensing or real-time monitoring of road traffic, among others. In the architecture, engineering and construction fields (AEC) UAVs have demonstrated to be an ideal technology due to their optimal performance in terms of time, precision, safety and cost. Given the rapid growth of interest in this technology, this research presents a critical review of the literature on the use of UAVs in architecture and urbanism to define the most widely used techniques and delimit the fields of application based on the experimentation published by the scientific community. A scientific mapping was carried out in two stages using the VOSviewer ${ }^{\mathrm{TM}}$ software: a scientometric and a bibliometric analysis. This technique allowed us to analyse a large body of literature and bibliographic data to obtain trends, patterns and directions of this domain of knowledge. Then, a literature review was presented, highlighting the relevant information identified in the previous analysis. The fields of application of UAVs were delimited and the most commonly used payload types and the most appropriate post-processing techniques were specified, depending on the aerial mission objective. The fields of application identified included different techniques related to the generation of 3D models, land mapping, construction site monitoring, building surveying to detect structural damage and energy losses and urban remote sensing. The literature review showed that UAVs provide a useful multi-tasking tool at any stage of an architectural project. These techniques can be applied to buildings or public spaces from the design and construction processes when the project is initiated to the later stages of maintenance and inspection of the building during its life cycle.
\end{abstract}

Keywords: UAV; UAS; RPAS; drone; architecture; urbanism; construction; review; state-of-the-art; science mapping; VOSviewer

\section{Introduction}

Unmanned aerial vehicles (UAVs) are commonly known as UAS (Unmanned aerial systems) and RPAS (Remotely piloted aircraft systems). There are small distinctions between their meanings, although they are terms that are usually used interchangeably. While an UAV can fly autonomously without human intervention, a RPAS must be controlled by someone from a remote station even if the flight is in automatic mode. A UAS is a much broader term and describes all the systems that allow the operation of an UAV. Generally, all these systems are denominated drones.

In recent years, the use of UAVs has proliferated in the civilian sector, although originally these systems were designed for military applications. UAV technology in the 
military sector is more advanced than in others. Its development began to be explored during the wars of the 20th century. From the 1990s -when global positioning systems (GPS) became available to all users- a new market started to emerge in the civilian sector for UAVs. GPS development opened up the possibility of maintaining the position of an UAV in a global reference system in almost all parts of the world and in real time. In the early 2000s, UAVs became more popular because of the cost reductions and their technological development in different and functional platforms [1].

UAVs can be classified according to their design (fixed wing, helicopter and multirotor) and their maximum mass at take-off (up to $25 \mathrm{~kg}$, up to $150 \mathrm{~kg}$ and more than $150 \mathrm{~kg}$ ). The most commonly used UAVs to carry out tasks in the civil sector -particularly in urban environments- are the multi-rotor and low weight types due to the restrictive regulations of the countries for safety reasons. The legislation of each country establishes a maximum weight of the UAV to be able to operate it in cities. These systems are propelled by multiple rotating engines attached to their fuselage. Inside the fuselage are the electronic equipment and under it the payload (sensors) and the landing gear. The weight of all these components is crucial to perform civil tasks.

In recent years, researchers have shown great interest in the use of UAVs for civilian purposes such as search and rescue [2], remote sensing [3], construction and infrastructure inspection [4], agricultural precision [5], delivery of goods [6], real-time monitoring of road traffic [7], surveillance [8] and providing wireless coverage [9]. Their characteristics of multi-rotors such as hover, stability, manoeuvrability, vertical take-off and landing (VTOL) and low maintenance cost, make them the optimal system to carry out tasks that require low speeds, low heights and stable hover in the air such as taking photographs or taking measurements.

UAVs are an ideal technology for architecture, engineering and construction fields (AEC) as they can access spaces that are unsafe and inaccessible to human workers. They have better features in terms of time, accuracy, safety and costs compared to conventional methods [10]. They also allow the reception of real-time telemetry data during a flight thanks to the connection of the UAV station with any smartphone device. It is possible to know instantly the percentage of battery charge, the height, the distance to the pilot, the distance to the landing point, the ascent speed, the forward speed, the GPS coverage status, the reception of the camera images, etc. The most commonly used sensors for telemetry in this field are commercial cameras as the basis for image and video acquisition, followed by laser scanners, thermal cameras, radio frequency and ultrasonic beacon system [11]. The most important constraints on UAV operation are the lack of autonomy due to short battery life, the loss or presence of GPS signal interference (as occurs indoors), climatic conditions and the restrictive regulatory systems to operate in urban spaces $[1,12,13]$.

Given the rapid growth of interest in this technology, this article presents a critical review of the literature on the use of UAVs in architecture and urbanism to delimit the fields of application based on the experimentation carried out by the scientific community. Special emphasis was placed on the development of the techniques identified: the types of payload used and the most appropriate post-processing techniques according to the objective of the inspection carried out with the UAV. In addition, the most recent technological advances and the main challenges in the different fields of application were identified.

In order to carry out a critical and objective literature review, a science mapping was developed. Scientific mapping is an interdisciplinary field that deals with scientific database information in the areas of scientometrics, citation analysis, computer science in the areas of information visualization, visual analytics $\backslash$ and data mining $[14,15]$. A science mapping allows to structure conceptually, intellectually and socially disciplines, scientific domains or research fields [16-18]. In addition, it allows researchers to make systematic discoveries related to the literature by linking concepts that may go unnoticed in studies that conduct the review manually [19]. Other researchers have carried out similar review tasks [20-22], but none of them were carried out on the basis of a previous science mapping or with such an extensive database of literature. 
This research follows the following structure: the materials and methods carried out for the science mapping are detailed in Section 2. The results of the literature analysis are shown in Section 3 and the literature review is exposed in Section 4. Finally, the conclusions obtained throughout the development of this research are presented in Section 5.

\section{Materials and Methods}

To achieve the purpose of this research, a science mapping -which includes a scientometric analysis and a bibliometric analysis- was made [23]. Scientometric analysis is used to analyse a large body of literature and bibliographic data to identify areas of activity, key specialities, evolutionary stages and dynamics of a body of literature [24]. It allows to limit an extensive bibliography in different areas, providing a structure of the most relevant terms used in the literature. Bibliometric analysis is carried out afterwards and is used to study and evaluate in depth the literature per se following this structure.

The sequence of work of the developed science mapping analysis has different steps. The first step was the choice of a bibliographic database and a science mapping software tool. The second step was the collection of literature from the bibliographic database after a pre-processing using search filters. The third step was the handling of the literature data in the science mapping software for the construction and visualization of network map. The fourth step was the analysis of the results obtained from the literature data. This step was based on the extraction of useful knowledge and the interpretation of the results in order to make the literature review and draw the most important conclusions [15]. This research follows this structure in the following sections: the first three steps were explained in the section of materials and methods; and the fourth step was developed in the section of results and literature review.

\subsection{Science Mapping Tools}

This section deals with the first step of the work sequence. Some tools to carry out a scientific mapping on any area of knowledge were studied.

Currently there are online bibliographic databases where thousands of scientific papers are stored and can be retrieved. Some important bibliometric sources are Google Scholar $^{\mathrm{TM}}$, Web of Science ${ }^{\mathrm{TM}}$ and Scopus ${ }^{\mathrm{TM}}$. Google Scholar ${ }^{\mathrm{TM}}$ is a free tool open to the general public. The Google Scholar ${ }^{\mathrm{TM}}$ database is part of the Google search engine and provides a large amount of information, but in a poorly ordered and updated way [25]. In addition, downloading large data sets from Google Scholar ${ }^{\mathrm{TM}}$ is a difficult process and does not allow to download the entire set [15]. Web of Science ${ }^{\mathrm{TM}}$ and Scopus ${ }^{\mathrm{TM}}$ are databases of commercial suppliers that require a fee for access. Web of Science ${ }^{\mathrm{TM}}$ offers publications with records indexed and archived since 1900, Scopus ${ }^{\mathrm{TM}}$ includes articles from 1966. Eric Archambault et al. [26] compared the data collected from Web of Science ${ }^{\mathrm{TM}}$ and Scopus ${ }^{\mathrm{TM}}$ and found a high correlation between the articles and the citations. Hence, they demonstrated that there were no major differences in the results of a scientific mapping carried out with the two databases.

To avoid problems of duplication of publications between the different databases, only one of them was used. After comparing the three proposed databases, Scopus ${ }^{\mathrm{TM}}$ was finally used due to its wide range of coverage of scientific publications [27] and its faster indexing process which makes it possible to compile the latest literature [28]. The Scopus $^{\mathrm{TM}}$ database was developed by Elsevier [29].

A comprehensive collection of scientific mapping software is available for bibliometric analysis, which allows for the mapping and visualization of a given set of large-scale academic data in a field of knowledge. Manuel Cobo et al. [15] and Katy Börner et al. [30] provided a generic list of software tools used by the scientific community to perform scientometric analysis.

In order to select the tool needed for this study, the characteristics and limitations of various scientometric software were analysed: CiteSpace ${ }^{\mathrm{TM}}$, CitNetExplorer ${ }^{\mathrm{TM}}$ and VOSviewer $^{\mathrm{TM}}$. CiteSpace ${ }^{\mathrm{TM}}$ is a software tool used to identify, examine and display 
patterns and trends in the scientific literature. It allows dynamic visualizations of the evolution of bibliometric networks over time. Its graphical interface offers many options available to the user which is quite confusing for new users. The graphic results are not as easy to interpret as those offered by other tools [31]. CitNetExplorer ${ }^{\mathrm{TM}}$ interactively visualises maps of the relationship between documents. This tool allows to explore a network of publication citations interactively: it is possible to examine a network that includes thousands of publications until it is gradually reduced to a small sub-network of less than one hundred documents [31]. VOSviewer ${ }^{T M}$ is used to create and visualize bibliometric network maps with options similar to CiteSpace ${ }^{\mathrm{TM}}$ and CitNetExplorer ${ }^{\mathrm{TM}}$. This tool focuses the graphic representation of network maps to help in the interpretation of the extracted data. Against to the other tools, VOSviewer ${ }^{\mathrm{TM}}$ constructs the bibliographic networks in distance-based visualisations which makes it the most suitable method for visualizing large networks (e.g., at least 100 items). It is appropriate to represent big maps since zoom functionality, special labelling algorithms, and density metaphors are used. In addition, VOSviewer ${ }^{\mathrm{TM}}$ allows to view any two-dimensional map based on distance, regardless of the mapping technique used to construct the map. VOSviewer ${ }^{\mathrm{TM}}$ can display maps constructed using any suitable mapping technique. This software integrates the VOS cartography which enables it to be used to build and visualize the maps without the use of any other tool [32]. In addition, the scientific community has validated the VOSviewer $^{\mathrm{TM}}$ software as a useful tool for performing scientometric analysis in different fields of science [33-35]. A. Niñerola et al. (2019) used the software to review the relevant literature, from a large database (2647 documents), mapping the main trends in the area of the sustainable tourism [36]. On the other hand, J. Taveira de Souza et al. (2019) used the software to analyse just 39 articles and also obtained visually maps and valuable information about smart cities. M. Gough et al. (2020) demonstrated that VOS-viewer ${ }^{\mathrm{TM}}$ software provided important features for scientometric analysis reporting new trends in its research on electricity use and production [37]. The tool's developers Jan van Eck and Ludo Waltman (2017) analysed the software extensively and performed sophisticated cluster analysis showing that it is not necessary to have a deep knowledge of clustering techniques or advanced computer skills to use the software [38].

Due to these qualities, VOSviewer ${ }^{\mathrm{TM}}$ version 1.6.15 was used to carry out the scientometric analysis of the bibliometric network. The program is freely available to the bibliometric research community. This tool was developed by Nees Jan van Eck and Ludo Waltman at the Centre for Science and Technology Studies at Leiden University [39].

\subsection{Bibliographic Data Collection}

In this section a compilation of the information to be analysed was made. The literature search was carried out on Scopus ${ }^{\mathrm{TM}}$ which shows lists of 20-200 articles per page and allows the creation of lists of documents that can be downloaded.

Some keywords were chosen and searched in the titles, abstracts and keywords of the article database. The keywords were defined because they were considered synonyms or words related to the objective of the analysis: to identify the different applications of the UAV in the field of architecture and urbanism. As a result, a list of keywords related to the words architecture, applications and urbanism was created (such as building, construction, maintenance, monitoring, city, urban planning, etc.). These keywords were subjected to multiple combinations with the words: UAV, UAS, RPAS or drone that comprise the same concept.

More than 1000 results were compiled and processed by the filtering. Considering such a large number of publications introduces noise into the data complicating the process of analysis and interpretation of results [23]. The results of Scopus ${ }^{\mathrm{TM}}$ can be refined by year of publication, language, document type, subject area and source type. The search was limited to articles after 2010. Only articles and reviews in English language were chosen. Only articles and reviews from scientific journals were used in this review, as they tend to present higher quality and more comprehensive information than other types of 
publications. Subject areas not related to the domain of engineering and environmental sciences were excluded (e.g., chemical, agriculture, pharmacology, medicine, etc.). The searches were limited to articles from Q1 (quartile 1) and Q2 (quartile 2) journals, so the papers analysed in this study are peer-reviewed and of a high standard. The quartile is an indicator that is used to evaluate the relative importance of a journal within the total number of journals in its research area.

The result was 460 documents that were processed manually, excluding articles that were off-topic. Scopus offers a pre-visualisation of the abstract and highlights the presence of key words in it, making this process faster [25]. In October 2020 the database of literature to be analysed was limited to 206 articles and 29 review articles for further analysis. All the bibliographical data of the 235 documents were extracted and downloaded from Scopus ${ }^{\mathrm{TM}}$ forming the dataset of the present study. Each item extracted from Scopus ${ }^{\mathrm{TM}}$ contains information about the authors, institutional affiliations, country, publication year, source journal, title, abstract, keywords and references. The process of searching the literature is shown in Figure 1.
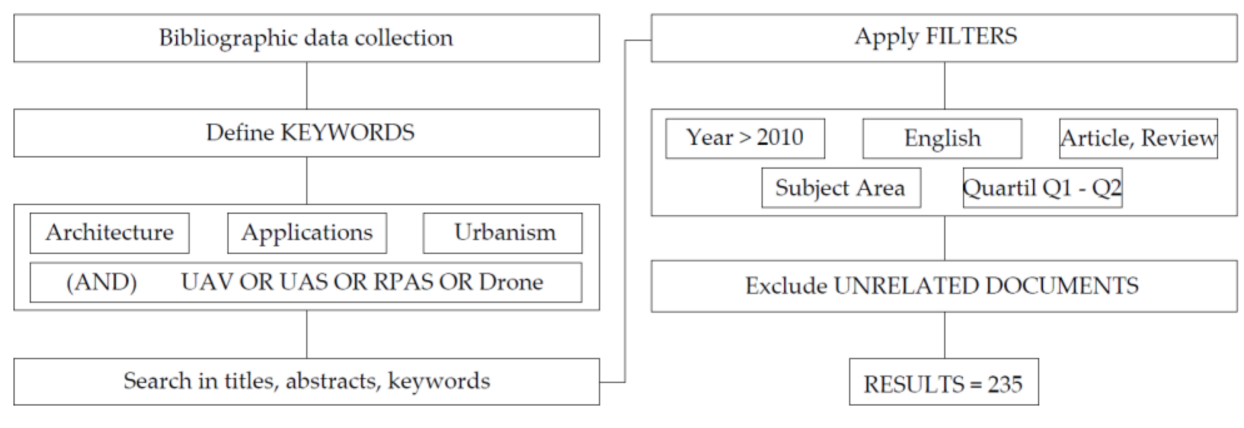

Figure 1. Bibliographic data collection process.

\subsection{Construction and Visualization of Network Maps}

The data extracted from the Scopus database was entered into VOSviewer ${ }^{\mathrm{TM}}$ to graphically represent the bibliometric maps. VOSviewer ${ }^{\mathrm{TM}}$ allows users to load the bibliographic records from Google Scholar ${ }^{\mathrm{TM}}$, Web of Science ${ }^{\mathrm{TM}}$ and Scopus ${ }^{\mathrm{TM}}$. The bibliographic base of 235 articles was processed in the software to create maps based on web data and to visualize and explore these maps.

A bibliometric network created in VOSviewer ${ }^{\mathrm{TM}}$ consists of nodes and links. The nodes are the units of analysis. The links between the nodes represent the connections between the items. These nodes and links can be displayed according to different types of analysis like co-authorship, co-occurrence, citation and bibliographic coupling. It should be noted that each network establishes the connections between the analysis units in a different way:

- In the co-authorship network, the distance between two nodes indicates their coauthorship relation, which is materialised in one line (link) depending on the number of documents of whom they have been co-authors.

- In the co-occurrence network, the link between two nodes depends on the number of documents in which they occur together.

- In the citation network, the distance between two nodes indicates their citation ratio, which is materialized in a line (link) depending on the number of times they have cited themselves.

- $\quad$ Finally, in the bibliographic coupling network, the link between two nodes depends on the number of times they have cited the same documents [32].

In this review, the units analysed were: authors, countries, source journals, documents and keywords. The network analyses performed for each item were the mentioned above: co-authorship, co-occurrence, citation and bibliographic coupling network. For proper field-normalized comparisons between authors, countries or institutions, VOSViewer ${ }^{\mathrm{TM}}$ allows two types of counting methods: full counting equalises the weight of all links 
between nodes (i.e., full counting gives equal weight to all co-authors of a research paper) and fractional counting, which divides the weight of links between nodes (i.e., fractional counting gives more weight to the main author and less weight to the co-authors). The purpose of fractional counting is to reduce the influence of collaborative publications. Normally the full counting approach is used, so this was the selected counting method [40]. Once the network analyses were constructed and visualized, the following step was taken useful knowledge from the attributes of each node and its links. These attributes can indicate the number of links of an item with other items (link strength) and the total strength of the links of an item (total link strength). They also provide information about the number of documents, citations and average year related to an item and its links. The size of the node and of the links varies according to these attributes, being larger in the graphics as they are more relevant in the literature. In addition, the network normalisation processes the nodes in the 2D space according to their relationship within the literature: strongly related nodes are placed close to each other, while weakly related nodes are placed far from each other. The arrangement of the nodes on the maps is carried out using VOS cartography included in the software and based on the technique of modularity-based clustering. This technique allows to assign the nodes to different clusters. Each cluster groups nodes that are closely related to each other. The color of a node is determined by the cluster to which the item belongs [31].

\section{Results}

The number of publications on the application of UAVs in architecture and urbanism over the last decade is illustrated in Figure 2. The first three years (2011 to 2014) were poorly productive with a low number of articles and no reviews. After 2014, the number of articles tripled compared to the previous year and continued to grow in the following years. 2018 became a turning point in the development and use of UAVs in this field of science as the number of articles and reviews doubled the average of the previous years. A stable trend in the number of publications can be observed from 2018 to the present.

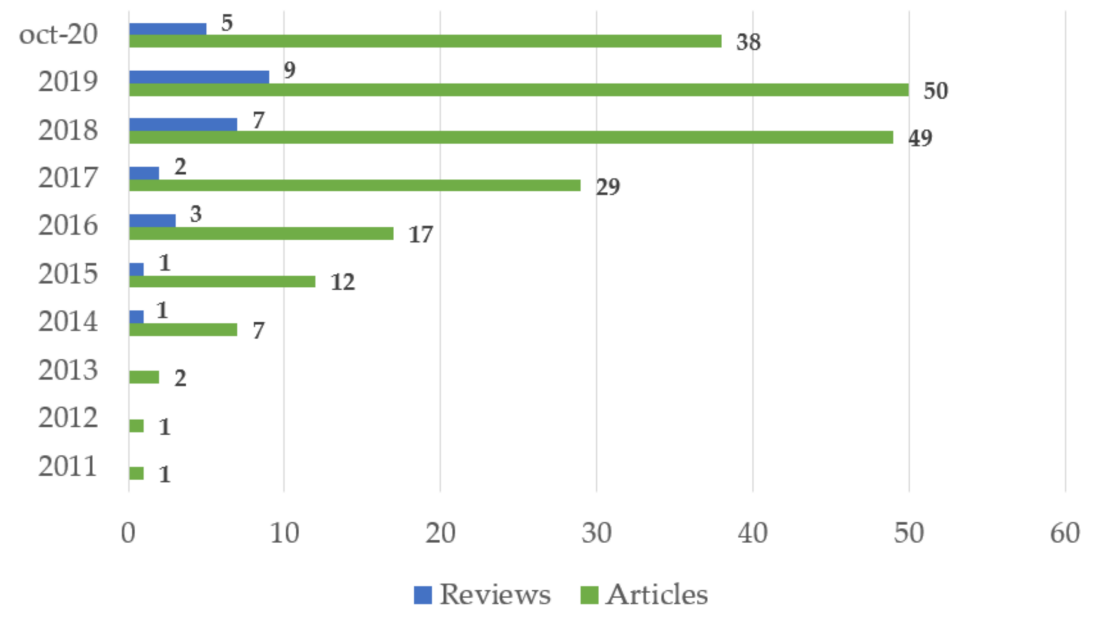

Figure 2. Number of articles and reviews for each year in the period 2011-October 2020.

The results obtained from the scientometric analysis with VOSviewer ${ }^{\mathrm{TM}}$ software are detailed below. The different items were analysed according to the different networks. They were divided into five subcategories: authors, countries, source journals, documents and keywords. Then, the results were discussed in order to make the bibliometric analysis and draw the most important conclusions about the use of UAV in architecture and urbanism.

\subsection{Authors}

The following section analyze the authors of the literature database according to the co-authorship, citation and bibliographic coupling networks. The analysis of the authors, their number of publications, co-authorship relations and number of citations, allows a 
deeper knowledge of the researchers that have most experienced the application of the UAVs in architecture and urban planning.

The three analyses were performed using the authors unit of the downloaded data to create a map by selecting a threshold with a minimum of two documents per author and a minimum of 20 citations per author, which led to the 52 most published and cited authors in the database (initially, 863 authors were identified). In the analysis, shown in Figure 3, each author is represented by a node. The colour of the nodes represents the average year of publication of an author. Table 1 shows the main authors with the most publications and citations, as well as additional information about their affiliation and average year of publication. The total link strength of each author is also shown, indicating the total strength of their links to other authors. It has to be noted that these networks are limited to the top 52 of productive researchers to facilitate the interpretation of the analysis, thus the link strength only reflects their connections (the rest of the researchers are not included).

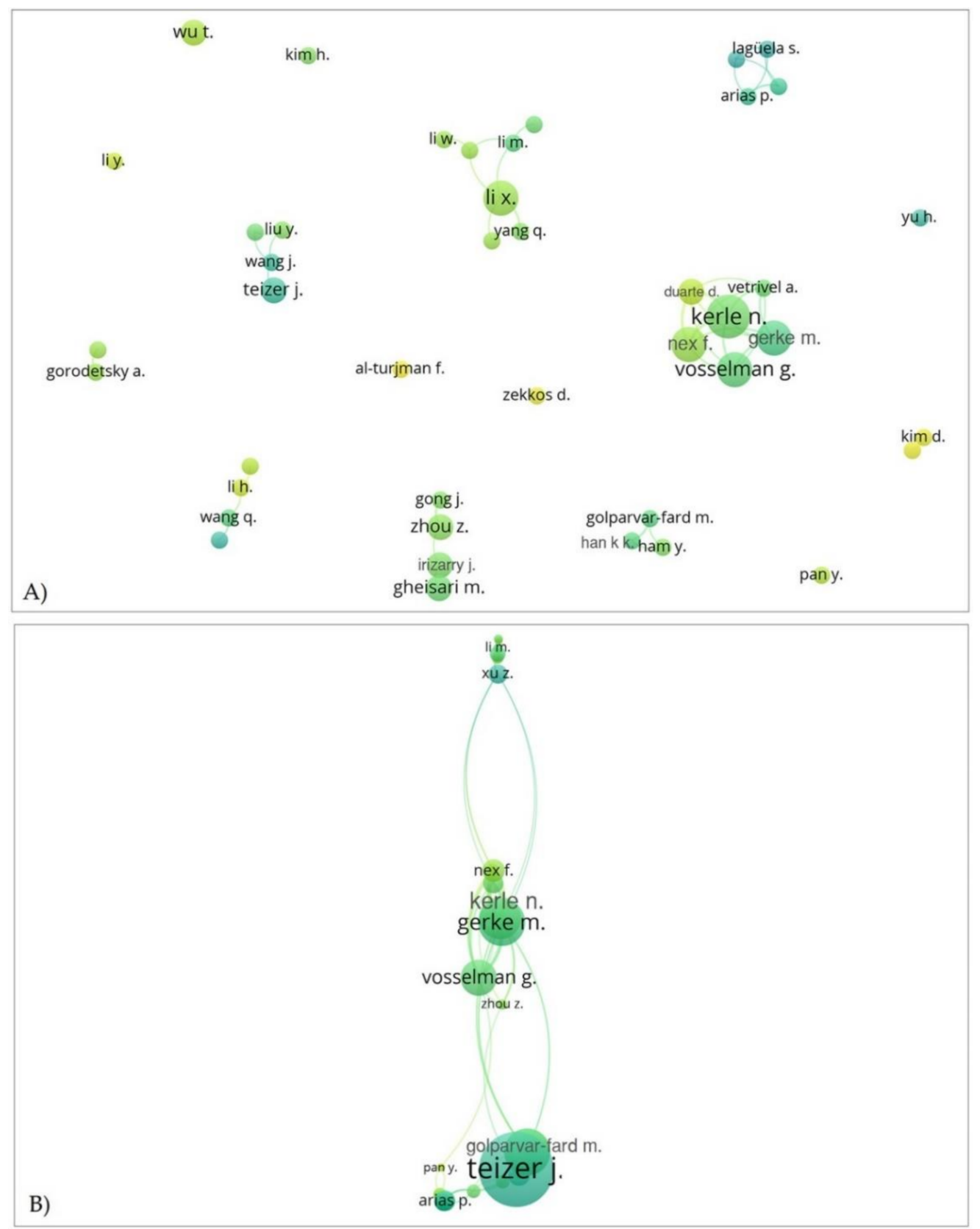

Figure 3. Cont. 


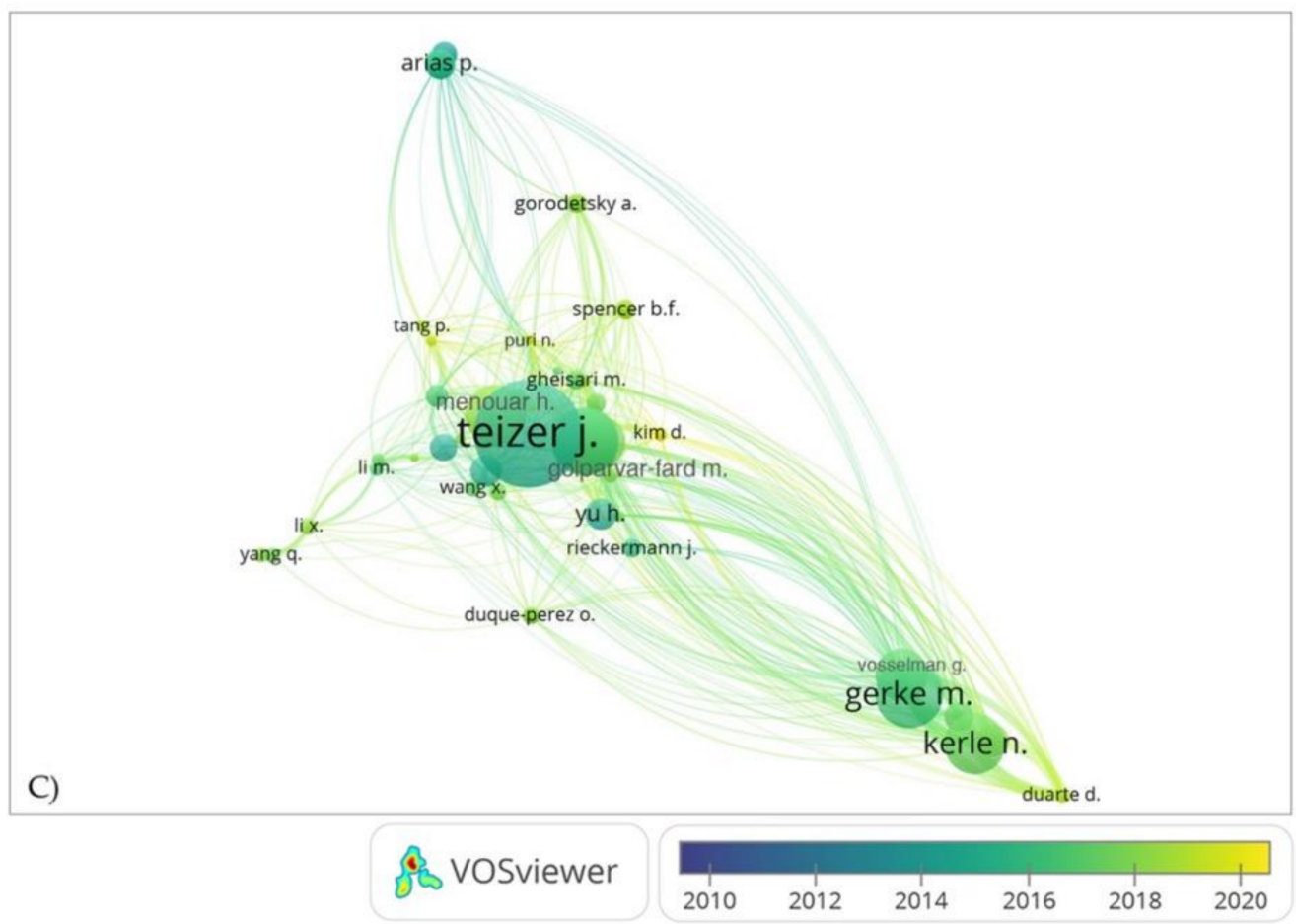

Figure 3. Authors network analysis. (A) Co-authorship network, (B) Citation network, (C) Bibliographic coupling network.

Table 1. Summary of network analyses. Authors with the highest number of publications and citations.

\begin{tabular}{|c|c|c|c|c|c|c|c|}
\hline Author & Organization & Publications & Citations & Year & $\begin{array}{c}\text { Co- } \\
\text { Authorship } \\
1\end{array}$ & Citation $^{1}$ & $\begin{array}{l}\text { Bibliographic } \\
\text { Coupling }{ }^{1}\end{array}$ \\
\hline Kerle, Norman & University of Twente & 5 & 226 & 2017 & 13 & 61 & 1379 \\
\hline Gerke, Markus & $\begin{array}{l}\text { University of } \\
\text { Braunschweig }\end{array}$ & 4 & 256 & 2016 & 10 & 46 & 1386 \\
\hline Vosselman, George & University of Twente & 4 & 184 & 2016 & 8 & 29 & 1086 \\
\hline Nex, Francesco & University of Twente & 4 & 102 & 2018 & 11 & 39 & 1590 \\
\hline Teizer, Jochen & Aarhus University & 3 & 463 & 2015 & 1 & 26 & 360 \\
\hline Irizarry, Javier & $\begin{array}{c}\text { Georgia Institute of } \\
\text { Technology }\end{array}$ & 3 & 54 & 2017 & 2 & 3 & 228 \\
\hline Duarte, Diogo & University of Coimbra & 3 & 39 & 2018 & 9 & 37 & 1076 \\
\hline Golparvar-fard, Mani & University of Illinois & 2 & 253 & 2016 & 3 & 13 & 260 \\
\hline Han, Kevin K. & NC State University & 2 & 253 & 2016 & 3 & 13 & 260 \\
\hline Menouar, Hamid & $\begin{array}{c}\text { Qatar Mobility } \\
\text { Innovations Center }\end{array}$ & 2 & 225 & 2018 & 0 & 1 & 7 \\
\hline Ham, Youngjib & Texas A\&M University & 2 & 179 & 2017 & 2 & 13 & 173 \\
\hline
\end{tabular}

In the co-authorship network (Figure 3A), the size of the nodes indicates the number of publications of each researcher. According to the number of publications, the authors with the most articles published are: Kerle, Norman (five publications), followed by Gerke, Markus, Vosselman, George and Nex, Francesco with four publications each one (Table 1). The links in Figure 3A reveal a strong evidence between the co-authorship relation of these authors together with Duarte, Diogo, showing the highest total link strength in terms of 
scientific collaboration (between 8-13). It can be seen that the greatest number of the most prolific authors is working in the same university (University of Twente in The Netherlands). The identified research group has collaborated with other European researchers from the Technical University of Braunschweig and the University of Coimbra. They are specialized in the identification and evaluation of structural damage in buildings, after a natural disaster, through the use of UAVs. In their published articles they discussed the evolution of the use of UAVs in this field, from the simple acquisition of descriptive images to generate three-dimensional point clouds, to more sophisticated object and segment-based methods. Their last research are focused on studies that improve and optimise the damage detection process by using deep learning approaches and convolutional neural networks (CNN) [41-45]. Another scientific collaboration identified is between the prolific American authors: Golparvar-fard, Mani, Han, Kevin K and Ham, Youngjib who have not published many articles, but do collect a high number of citations in their research $(253,253$ and 179 citations, respectively). They are focused on the application of camera-equipped UAVs for visually monitoring construction sites of buildings. They proposed methods to improve the process of collecting and analysing visual data collected daily and weekly from building site inspections $[12,46,47]$.

In the citation network (Figure 3B) and in the bibliographic coupling network (Figure 3C), the size of the nodes indicates the number of citations of each researcher. According to the number of citations, the most frequently cited authors are: Teizer, Jochen (463 citations), followed by Gerke, Markus (256), Golparvar- fard, Mani and Han and Kevin K with 253 citations for each one (Table 1). Unlike the co-authoring network where the most prolific authors who collaborate together belong to the same region (there is no collaboration between the authors from different continents), the citation network (Figure 3B) and bibliographic coupling network (Figure 3C) show connecting links between all of them.

The authors with the most documents and citations published their research between 2015 and 2018. It must be highlighted the case of Teizer, Jochen as a pioneer in research in this area of research. This is demonstrated by the colour of its node which sets the average year of its publications in 2015. Its high number of citations are attributed to the publication of its research at an early date, making it a source of guidance and reference for other researchers. His research focused on 3D mapping of terrains, safety planning and accident prevention on construction sites using UAVs $[1,48,49]$.

\subsection{Countries}

In this section, countries were analysed according to three criteria: co-authorship, citation and bibliographic coupling networks. These networks between regions make possible to identify the places where this research area has been more investigated.

The three analysis were performed using the countries unit of the downloaded data to create a map. Fifty-Two countries were initially identified and no limits or thresholds were set. Each country is represented by a node whose colour depends on the average year of publication by country (Figure 4). The main countries with the highest number of publications and citations (five European countries, three Asian countries, two American countries and one from Oceania) are shown in Table 2 along with more information from the analysis (like the region, the average year of publication and the total link strength). In this case, the link strength indicates the connections between all the countries because no previous thresholds were established. 


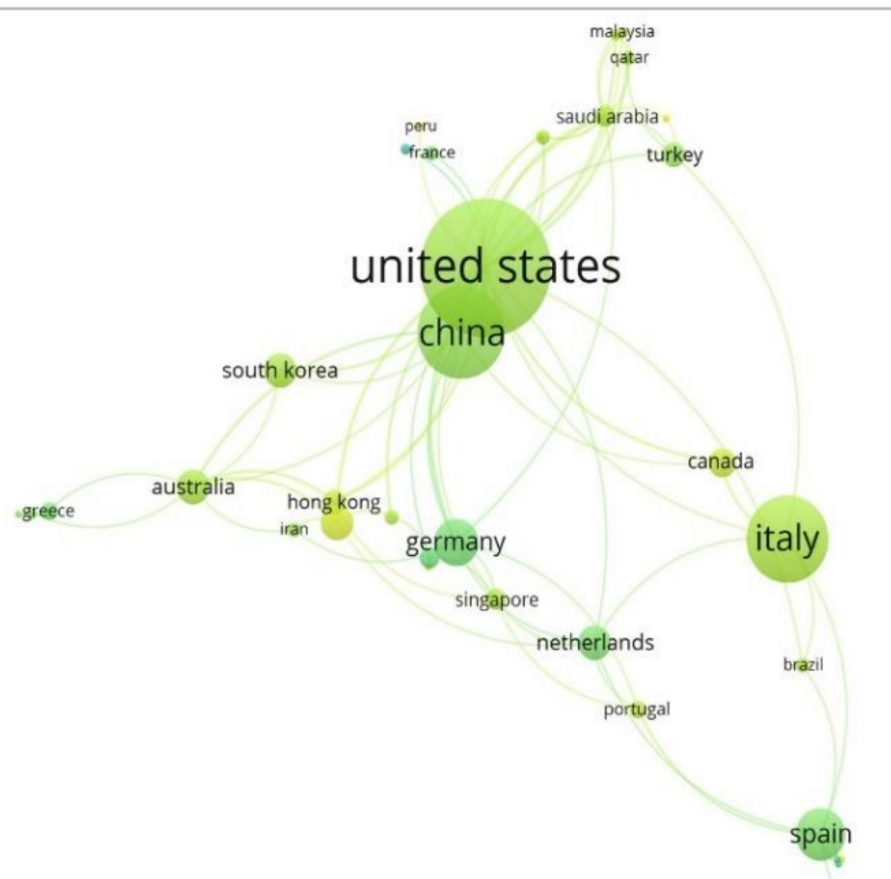

A)

taiwan

cuba

netherlands greece

iran singapore south korea

canada brazil

spain

germany

switzerland

italy

united states

china

taiwan hongkon

france

saudi arabia

qatar .

B)

jordan

Figure 4. Cont. 


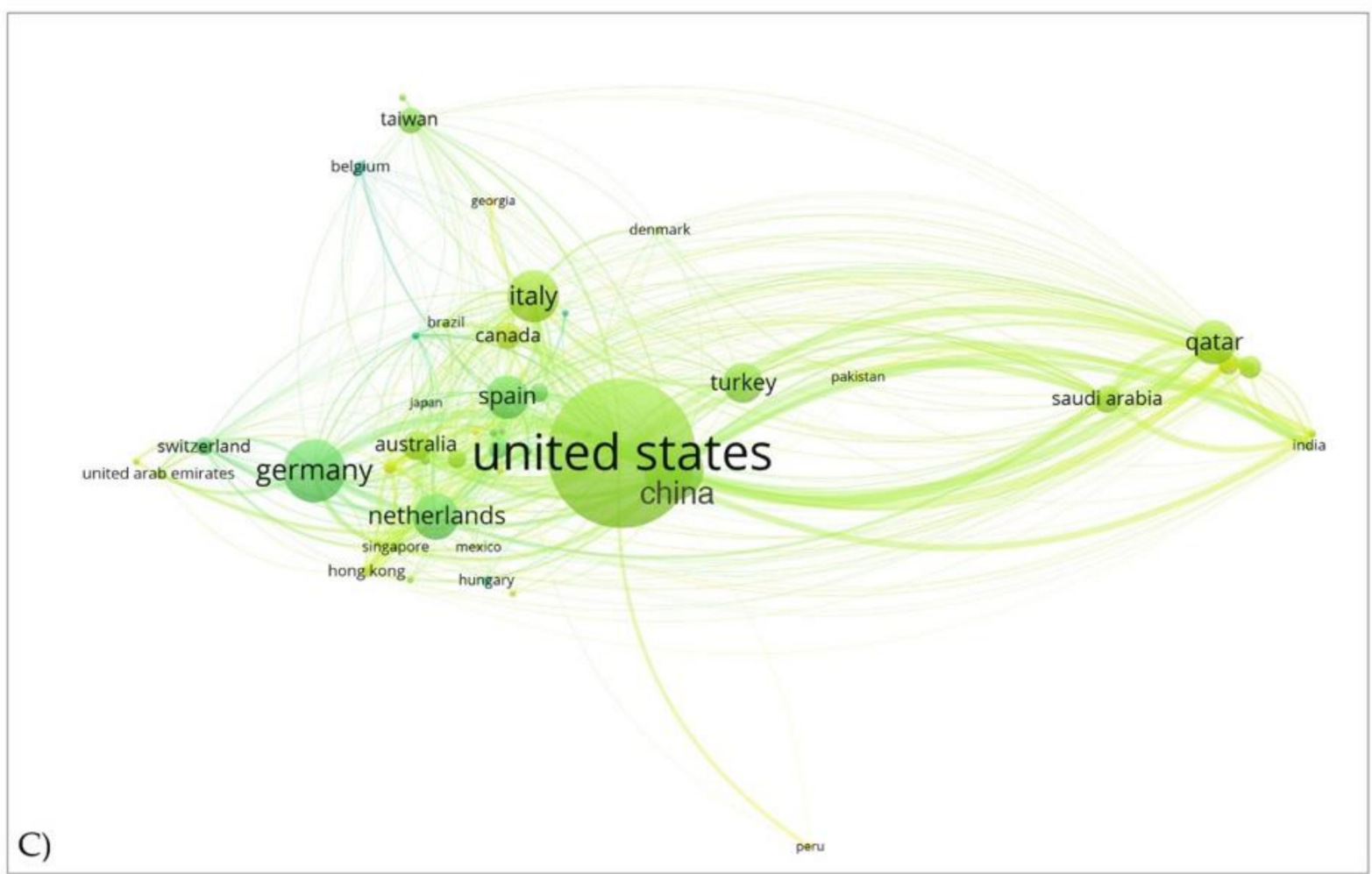

VOSviewer

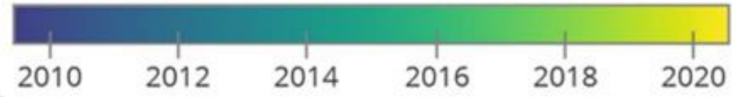

Figure 4. Countries network analysis. (A) Co-authorship network, (B) Citation network, (C) Bibliographic coupling network.

Table 2. Summary of network analyses. Countries with the highest number of publications and citations.

\begin{tabular}{|c|c|c|c|c|c|c|c|}
\hline Country & Region & Publications & Citations & Year & Co-Authorship ${ }^{1}$ & Citation $^{1}$ & $\begin{array}{l}\text { Bibliographic } \\
\text { Coupling } 1\end{array}$ \\
\hline USA & America & 69 & 1902 & 2018 & 43 & 141 & 6629 \\
\hline China & Asia & 39 & 527 & 2017 & 20 & 42 & 3078 \\
\hline Italy & Europe & 36 & 437 & 2018 & 9 & 31 & 1331 \\
\hline Spain & Europe & 18 & 330 & 2017 & 9 & 30 & 861 \\
\hline Germany & Europe & 15 & 566 & 2017 & 13 & 55 & 1588 \\
\hline Netherlands & Europe & 10 & 361 & 2017 & 7 & 40 & 961 \\
\hline Australia & Oceania & 10 & 199 & 2018 & 11 & 23 & 1318 \\
\hline South Korea & Asia & 10 & 108 & 2018 & 4 & 9 & 507 \\
\hline UK & Europe & 10 & 64 & 2019 & 9 & 21 & 962 \\
\hline Canada & America & 8 & 169 & 2018 & 5 & 13 & 627 \\
\hline Qatar & Asia & 3 & 346 & 2018 & 7 & 21 & 1910 \\
\hline
\end{tabular}

In the co-authorship network (Figure $4 \mathrm{~A}$ ), the size of the nodes indicates the number of publications of each country. According to the number of publications, the countries with more articles published are: the USA (69 publications), followed by China (39), Italy (36), Spain (18) and the Netherlands (15), as can be seen in Table 2. The links in Figure $4 \mathrm{~A}$ show co-authoring relationships between all countries. The nodes of the USA and China have a strong collaborative relationship with the rest of countries as their total 
link strength indicates (43 and 20). In Europe, Germany stands out as the country with the highest rate of collaboration (13), despite not having as many articles published as other European countries.

In the citation network (Figure 4B) and in the bibliographic coupling network (Figure 4C), the size of the nodes indicates the number of citations of each country.

According to the number of citations, the most frequently cited countries are: the USA (1902 citations), followed by Germany (566), China (527) and Italy with 437 citations (Table 2). As in the co-authored map, the USA and China are positioned as the countries with the highest total link strength ratios in terms of citations in both maps (Figure 4B,C). The same pattern is repeated in terms of co-authorship and citation: both nodes are positioned centrally and some Middle East countries such as Saudi Arabia, Qatar and Turkey are grouped together and tend to move away from the rest of the countries. It is remarkable that Qatar has a high citation rate (346 citations) despite having published only three articles and the UK on the opposite side with only 64 citations in 10 publications.

It can be seen that researchers in Europe were the pioneers in researching the applications of UAVs in architecture and urbanism with an average publication year set at 2017.

\subsection{Source Journals}

The following section analyses the most cited journals with the most articles published in the area of research about the use of UAVs in construction and urban planning. The analysis of the academic journals with the most publications in an area of knowledge is useful for the reader in the search for better sources of information and for the author in the choice of a journal to publish a research.

By selecting the source journal unit of analysis, two analyses were carried out: citation and bibliographic coupling. From 113 total journals identified, 38 had a minimum of two documents published. In the analysis, shown in Figure 5, each journal is represented by a node whose colour depends on its average year of publication. The main journals with the highest number of documents and citations are shown in Table 3, plus more information about the subject area, the $\mathrm{H}$ index, the average year of publication and the total link strength. The H index is based on the productivity and impact of the scientific journal. The total link strength is calculated on the basis of the connections between the 38 documents.

In the citation network (Figure 5A), the size of the nodes indicates the number of citations of each journal. According to the number of citations, the most frequently cited journals are: Automation in construction (1180 citations), followed by IEEE Communications magazine (252), Remote sensing (205), IEEE Access (193) and Computer-aided civil and infrastructure engineering with 109 citations (Table 3). They are grouped into three subject areas: building and construction, engineering and computer science. It is worth highlighting the case of IEEE Communications magazine as the second most cited journal (252 citations), second largest $\mathrm{H}$ index (231) and only two publications in the field. In contrast, Energies has the lowest rate with 22 citations and four publications. The journal with the highest $\mathrm{H}$ index (258) is Renewable and sustainable energy reviews.

In the bibliographic coupling network (Figure 5B), the size of the nodes indicates its number of publications. According to the number of publications, the journals with the most articles published are: Automation in construction (37 publications), followed by Remote sensing (16), IEEE Access (9), ISPRS International journal of geo-information (6) and Sensors with five publications (Table 3). They are grouped into three subject areas: building and construction, engineering and earth and planetary sciences. In both Figure 5A,B, the Automation in construction node acquires a central position and connects the other nodes; it becomes the most cited element with the highest total link strength (20 and 443). Some journals with the same topic appear closer together, as shown in Figure 5B: in the centre, journals related to building and construction, engineering and renewable energy; at the bottom, journals related to earth and planetary sciences and arts and humanities; and at the top journals related to computer science. 

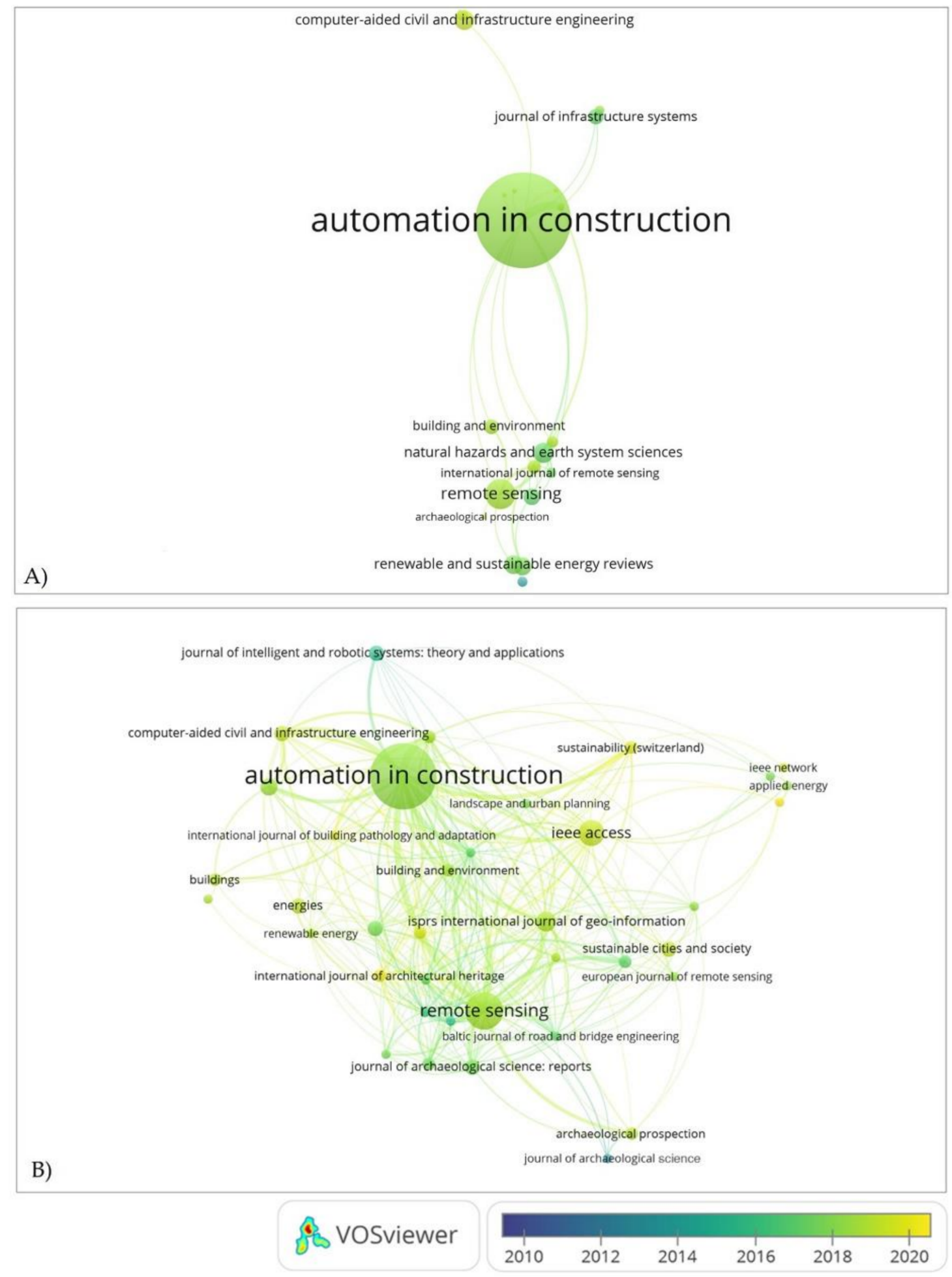

Figure 5. Source journals network analysis. (A) Citation network, (B) Bibliographic coupling network.

The journal with the oldest average publication per year, dated in 2015, is Journal of intelligent and robotic systems, theory and applications; the most recent, dated in 2019, are IEEE Access, Computer-aided civil and infrastructure engineering and Sustainable cities and society. 
Table 3. Summary of network analyses. Source journals with the highest number of publications and citations.

\begin{tabular}{|c|c|c|c|c|c|c|c|}
\hline Source Journal & Area & H Index & Publications & Citations & Year & Citation $^{1}$ & $\begin{array}{l}\text { Bibliographic } \\
\text { Coupling } 1\end{array}$ \\
\hline $\begin{array}{l}\text { Automation in } \\
\text { construction }\end{array}$ & $\begin{array}{l}\text { Building and } \\
\text { construction }\end{array}$ & 107 & 37 & 1180 & 2017 & 20 & 443 \\
\hline Remote sensing & $\begin{array}{c}\text { Earth and } \\
\text { planetary sciences }\end{array}$ & 99 & 16 & 205 & 2018 & 13 & 390 \\
\hline IEEE Access & Engineering & 86 & 9 & 193 & 2019 & 6 & 112 \\
\hline $\begin{array}{l}\text { ISPRS International } \\
\text { journal of } \\
\text { geo-information }\end{array}$ & $\begin{array}{c}\text { Earth and } \\
\text { planetary sciences }\end{array}$ & 35 & 6 & 63 & 2018 & 12 & 163 \\
\hline Sensors & Engineering & 153 & 5 & 47 & 2018 & 1 & 63 \\
\hline $\begin{array}{l}\text { Computer-aided civil } \\
\text { and infrastructure } \\
\text { engineering }\end{array}$ & Computer science & 76 & 4 & 109 & 2019 & 2 & 107 \\
\hline $\begin{array}{c}\text { Renewable and } \\
\text { sustainable energy } \\
\text { reviews }\end{array}$ & Renewable energy & 258 & 4 & 102 & 2017 & 2 & 38 \\
\hline $\begin{array}{l}\text { Journal of } \\
\text { archaeological science: } \\
\text { reports }\end{array}$ & $\begin{array}{c}\text { Arts and } \\
\text { humanities }\end{array}$ & 21 & 4 & 96 & 2017 & 5 & 66 \\
\hline $\begin{array}{c}\text { Journal of intelligent } \\
\text { and robotic systems: } \\
\text { theory and } \\
\text { applications }\end{array}$ & Computer science & 69 & 4 & 95 & 2015 & 0 & 24 \\
\hline $\begin{array}{l}\text { Sustainable cities and } \\
\text { society }\end{array}$ & Renewable energy & 43 & 4 & 35 & 2019 & 0 & 19 \\
\hline Energies & Engineering & 78 & 4 & 22 & 2018 & 0 & 15 \\
\hline $\begin{array}{l}\text { Natural hazards and } \\
\text { earth system sciences }\end{array}$ & $\begin{array}{c}\text { Earth and } \\
\text { planetary sciences }\end{array}$ & 90 & 3 & 108 & 2017 & 12 & 77 \\
\hline $\begin{array}{l}\text { Building and } \\
\text { environment }\end{array}$ & $\begin{array}{l}\text { Building and } \\
\text { construction }\end{array}$ & 138 & 3 & 71 & 2018 & 3 & 70 \\
\hline $\begin{array}{l}\text { IEEE Communications } \\
\text { magazine }\end{array}$ & Engineering & 231 & 2 & 252 & 2017 & 6 & 12 \\
\hline
\end{tabular}

${ }^{1}$ Total Link Strength.

\subsection{Documents}

In this section, articles from the database were analysed according to the citation and bibliographic coupling networks. These networks make possible a better understanding of the theoretical foundations of the most cited documents.

The two analyses were performed using the documents unit of the downloaded data to create a map by selecting a threshold with a minimum of 10 citations per document; which led to the 113 most cited articles in the database. Each article is represented by a node whose size depends on the number of citations and the colour depends on the year of publication (Figure 6). The most cited articles are shown in Table 4 along with more information from the analyses such as the field of application of the UAVs in the research, the average year of publication, the link strength and the total link strength. The link strength and the total link strength are calculated on the basis of the connections between the 113 documents. 

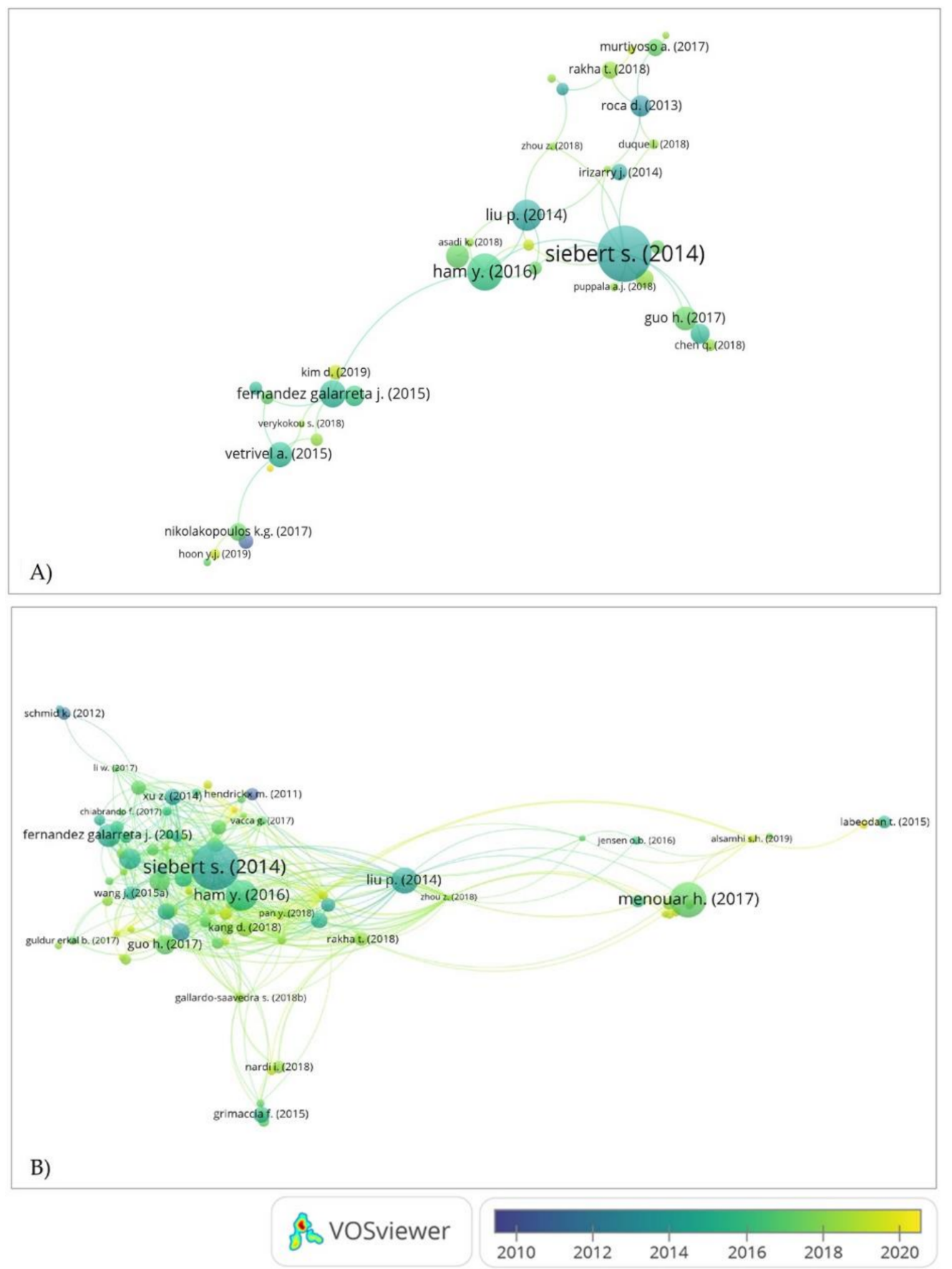

Figure 6. Documents network analysis. (A) Citation network, (B) Bibliographic coupling network.

According to the number of citations, the most frequently cited documents are: Mobile 3D mapping for surveying earthwork projects using an Unmanned Aerial Vehicle (UAV) system by Siebert S. (356 citations) [1], followed by UAV-Enabled intelligent transportation systems for the smart city: Applications and challenges by Menouar H. (219) [50], Visual monitoring of civil infrastructure systems via camera-equipped Unmanned Aerial Vehicles (UAVs): a review of related works by Ham Y. (172) [12], A review of rotorcraft Unmanned Aerial Vehicle (UAV) developments and applications in civil engineering by Liu P. (128) [22] and UAV-based urban structural damage assessment using object-based image analysis and semantic reasoning by Fernandez Galarreta J. [41] with 101 citations (Table 4). They are dated between 2014 and 2017, becoming the pioneering researches about the use of UAVs in architecture and urbanism. 
Table 4. Summary of network analyses. The most cited documents.

\begin{tabular}{|c|c|c|c|c|c|c|}
\hline Title Document & Author & Area & Citations & Year & Citation $^{1}$ & $\begin{array}{l}\text { Bibliographic } \\
\text { Coupling }{ }^{2}\end{array}$ \\
\hline $\begin{array}{l}\text { Mobile 3D mapping for surveying } \\
\text { earthwork projects using an } \\
\text { Unmanned Aerial Vehicle system }\end{array}$ & Siebert S. & $\begin{array}{l}\text { 3D modelling and } \\
\text { cadastral mapping }\end{array}$ & 356 & 2014 & 12 & 46 \\
\hline $\begin{array}{c}\text { UAV-Enabled intelligent } \\
\text { transportation systems for the } \\
\text { smart city: Applications and } \\
\text { challenges }\end{array}$ & Menouar H. & Smart city & 219 & 2017 & 2 & 8 \\
\hline $\begin{array}{c}\text { Visual monitoring of civil } \\
\text { infrastructure systems via } \\
\text { camera-equipped Unmanned } \\
\text { Aerial Vehicles: a review of related } \\
\text { works }\end{array}$ & Ham Y. & $\begin{array}{l}\text { Monitoring of } \\
\text { construction sites }\end{array}$ & 172 & 2016 & 9 & 51 \\
\hline $\begin{array}{l}\text { A review of rotorcraft Unmanned } \\
\text { Aerial Vehicle developments and } \\
\text { applications in civil engineering }\end{array}$ & Liu P. & $\begin{array}{l}\text { Applications in } \\
\text { civil engineering }\end{array}$ & 128 & 2014 & 7 & 49 \\
\hline $\begin{array}{l}\text { UAV-based urban structural } \\
\text { damage assessment using } \\
\text { object-based image analysis and } \\
\text { semantic reasoning }\end{array}$ & $\begin{array}{l}\text { Fernandez } \\
\text { Galarreta J. }\end{array}$ & $\begin{array}{l}\text { Building structural } \\
\text { damage assessment }\end{array}$ & 101 & 2015 & 6 & 24 \\
\hline $\begin{array}{l}\text { Identification of damage in } \\
\text { buildings based on gaps in 3D } \\
\text { point clouds from very high } \\
\text { resolution oblique airborne } \\
\text { images }\end{array}$ & Vetrivel A. & $\begin{array}{l}\text { Building structural } \\
\text { damage assessment }\end{array}$ & 86 & 2015 & 5 & 38 \\
\hline $\begin{array}{l}\text { Potential of big visual data and } \\
\text { building information modeling for } \\
\text { construction performance } \\
\text { analytics: An exploratory study }\end{array}$ & Han K.K. & $\begin{array}{l}\text { Monitoring of } \\
\text { construction sites }\end{array}$ & 81 & 2017 & 2 & 35 \\
\hline $\begin{array}{c}\text { Visualization technology-based } \\
\text { construction safety management: } \\
\text { A review }\end{array}$ & Guo H. & $\begin{array}{l}\text { Monitoring of } \\
\text { construction sites }\end{array}$ & 78 & 2017 & 2 & 23 \\
\hline $\begin{array}{l}\text { Low-cost aerial unit for outdoor } \\
\text { inspection of building façades }\end{array}$ & Roca D. & $\begin{array}{l}\text { Building energy } \\
\text { inspection }\end{array}$ & 65 & 2013 & 5 & 12 \\
\hline $\begin{array}{l}\text { Review of automatic feature } \\
\text { extraction from high-resolution } \\
\text { optical sensor data for UAV-based } \\
\text { cadastral mapping }\end{array}$ & Crommelinck S. & Cadastral mapping & 63 & 2016 & 1 & 49 \\
\hline $\begin{array}{l}\text { Autonomous UAVs for structural } \\
\text { health monitoring using deep } \\
\text { learning and an ultrasonic beacon } \\
\text { system with geo-tagging }\end{array}$ & Kang D. & $\begin{array}{l}\text { Building structural } \\
\text { damage assessment }\end{array}$ & 57 & 2018 & 0 & 41 \\
\hline $\begin{array}{l}\text { Integrating BIM and LiDAR for } \\
\text { real-time construction quality } \\
\text { control }\end{array}$ & Wang J. & $\begin{array}{l}\text { Monitoring of } \\
\text { construction sites }\end{array}$ & 57 & 2015 & 3 & 35 \\
\hline $\begin{array}{l}\text { Use of Unmanned Aerial Vehicle } \\
\text { for quantitative infrastructure } \\
\text { evaluation }\end{array}$ & Ellenberg A. & $\begin{array}{l}\text { Building structural } \\
\text { damage assessment }\end{array}$ & 56 & 2015 & 0 & 28 \\
\hline $\begin{array}{l}\text { Tridimensional reconstruction } \\
\text { applied to cultural heritage with } \\
\text { the use of camera-equipped UAV } \\
\text { and terrestrial laser scanner }\end{array}$ & Xu Z. & 3D modelling & 54 & 2014 & 0 & 24 \\
\hline
\end{tabular}


Sebastian Siebert et al. (2014) focused their research in the application of UAVs as measurement instruments for obtaining three-dimensional (3D) mapping data in large excavations and earthworks. They designed and explained in detail the components of an UAV specialised in carrying mapping of terrains, and then planned a flight at various excavations and generated 3D point clouds from digital images [1]. Hamid Menouar et al. (2017) studied the integration of UAVs as intelligent transport systems (ITS) in the cities of the future. They analysed the automation of urban elements like roads to implement UAVs in the monitoring of city traffic [50]. Youngib Ham et al. (2016) analysed the use of these platforms for inspection tasks on construction sites, mainly to monitor the work in progress, carry out safety inspections, quality supervisions and analysis of activity during construction [12]. Peter Liu et al. (2014) conducted a review from a general perspective on the use of UAVs in civil engineering such as energy plants, roads and other types of infrastructure buildings. They concluded that the most potential applications were in fields of construction site management, transportation, surveying, mapping and assessment of seismic and flood disasters [22]. Finally, Fernandez Galarreta J. et al. (2015) focused their research on the assessment of building structural damage through oblique images of very high resolution captured with UAVs. These images were subsequently subjected to machine learning techniques such semantic reasoning to facilitate the identification and classification (based on scores according to their level of severity) of damage [41].

In both analyses, nodes are labelled with the author's name of each document. In the citation analysis (Figure 6A), some of the main documents are linked, in particular, those with the highest link strength: Siebert S. (12), Ham Y. (9), Liu P. (7), Fernandez Galarreta J. (6), Vetrivel A. (5) and Roca D. (5). In the bibliographic coupling (Figure 6B), there are more connections between the main documents regardless of the field of application of UAVs in their research. It is worth highlighting the case of Menouar $\mathrm{H}$. as the second most cited document (219 citations) and the lowest total link strength (2 and 8). It appears further away from the central node conglomerate due to its field of application focused on a larger scale concept such as the intelligent city.

The fields of application of the UAVs identified in the top documents were: 3D modelling, cadastral mapping, monitoring of construction sites, building structural damage assessment, building energy inspection and smart city. The predominance of the colour blue on the maps should be noted with respect to the previous ones, which relates the high number of citations to the publication of these researches at a very early stage.

\subsection{Keywords}

The following section analyzes the keywords of the literature database according to the co-occurrence network. The analysis of keywords represents the core content of published documents and cover the range of areas researched within the boundaries of any domain.

The analysis was performed using the all keywords unit of the downloaded data to create a map by selecting a threshold with a minimum of five co-occurrences of a keyword, which led to the 87 most frequent keywords in the database (initially, 2346 keywords were identified). In the analysis, shown in Figure 7, each keyword is represented by a node whose size depends on the frequency of occurrence. The colours of the keywords represent clusters of terms that most often appear together. The automatic clustering process is useful to get an overview of the assignment of keywords to clusters and how the keyword clusters are related to each other. It is important to highlight that the clustering process does not cover keywords that are synonyms, only keywords that appear together in the articles. For this reason, it is logical that the different words used to refer to an unmanned aerial vehicle do not appear in the same cluster, as it is confusing for the reader to use all synonyms in the same research without defining the light differences between them previously. 


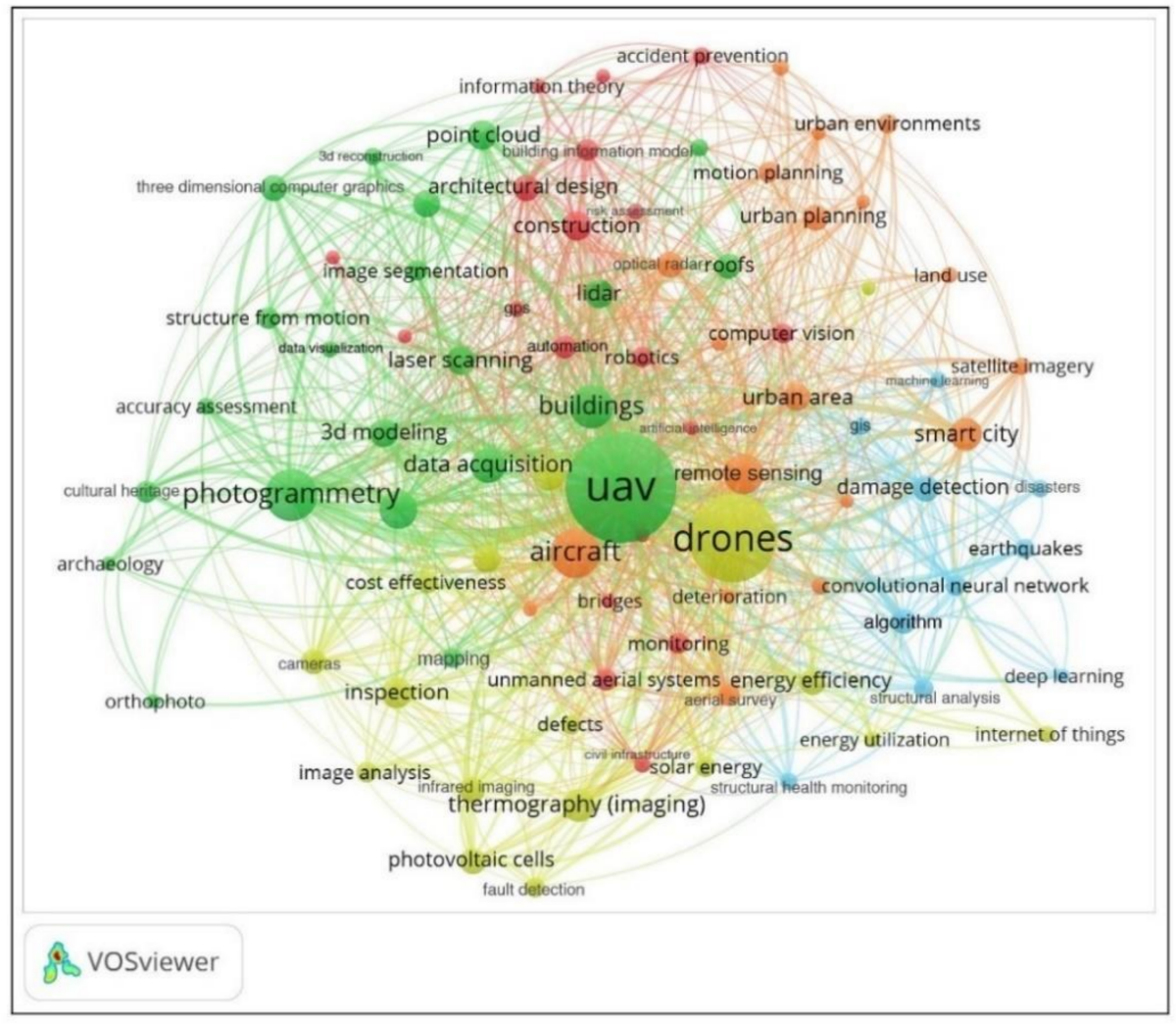

Figure 7. Keywords co-occurrence network analysis. Green colour: mapping and 3D modeling cluster, red colour: construction monitoring cluster, blue colour: structural damage detection cluster, yellow colour: energy efficiency prospection cluster, and orange colour: urban remote sensing cluster.

Table 5 shows the top keywords most frequent per cluster, with more information from the analysis, such as the average year of publication, the link strength and the total link strength.

Table 5. Summary of network analysis. The most frequent keywords per cluster.

\begin{tabular}{|c|c|c|c|c|c|}
\hline Keyword & Cluster & $\begin{array}{c}\mathrm{N}^{\mathrm{o}} \text { of } \\
\text { Co-Occurrences }\end{array}$ & Average Pub. Year & Link Strength & $\begin{array}{c}\text { Total Link } \\
\text { Strength }\end{array}$ \\
\hline UAV & & 137 & 2017 & 85 & 641 \\
\hline Photogrammetry & & 40 & 2017 & 59 & 201 \\
\hline Buildings & & 30 & 2017 & 64 & 173 \\
\hline Surveys & GREEN & 24 & 2018 & 67 & 159 \\
\hline Data acquisition & & 21 & 2017 & 60 & 129 \\
\hline Point cloud & & 16 & 2017 & 49 & 98 \\
\hline LiDAR & & 15 & 2017 & 55 & 105 \\
\hline Laser scanning & & 15 & 2016 & 54 & 86 \\
\hline Construction & & 16 & 2017 & 34 & 74 \\
\hline Architectural design & & 13 & 2017 & 36 & 74 \\
\hline Automation & & 11 & 2018 & 37 & 47 \\
\hline UAS & RED & 10 & 2018 & 41 & 64 \\
\hline $\begin{array}{l}\text { Building Information } \\
\text { Model }\end{array}$ & & 10 & 2016 & 32 & 63 \\
\hline Monitoring & & 9 & 2018 & 32 & 48 \\
\hline Robotics & & 9 & 2017 & 27 & 37 \\
\hline Accident prevention & & 7 & 2017 & 24 & 39 \\
\hline
\end{tabular}


Table 5. Cont.

\begin{tabular}{|c|c|c|c|c|c|}
\hline Keyword & Cluster & $\begin{array}{c}\mathrm{N}^{\mathrm{o}} \text { of } \\
\text { Co-Occurrences }\end{array}$ & Average Pub. Year & Link Strength & $\begin{array}{c}\text { Total Link } \\
\text { Strength }\end{array}$ \\
\hline Damage detection & & 13 & 2017 & 42 & 91 \\
\hline Algorithm & & 12 & 2018 & 45 & 101 \\
\hline $\begin{array}{c}\text { Convolutional neural } \\
\text { network }\end{array}$ & & 9 & 2019 & 38 & 71 \\
\hline Structural analysis & BLUE & 8 & 2018 & 29 & 55 \\
\hline Earthquakes & & 8 & 2017 & 26 & 51 \\
\hline $\begin{array}{l}\text { Structural health } \\
\text { monitoring }\end{array}$ & & 7 & 2018 & 29 & 47 \\
\hline Disasters & & 7 & 2017 & 31 & 42 \\
\hline Machine learning & & 6 & 2018 & 28 & 44 \\
\hline Drones & & 95 & 2018 & 82 & 488 \\
\hline Thermography (imaging) & & 19 & 2018 & 35 & 93 \\
\hline Image processing & & 18 & 2016 & 54 & 96 \\
\hline Inspection & YELLOW & 17 & 2018 & 44 & 100 \\
\hline Aerial photography & & 14 & 2017 & 44 & 90 \\
\hline Infrared imaging & & 13 & 2017 & 37 & 83 \\
\hline Energy efficiency & & 13 & 2017 & 35 & 73 \\
\hline Photovoltaic cells & & 13 & 2018 & 28 & 72 \\
\hline Aircraft & & 38 & 2017 & 64 & 201 \\
\hline Remote sensing & & 27 & 2018 & 58 & 164 \\
\hline Smart city & & 18 & 2018 & 30 & 62 \\
\hline Urban area & ORANGE & 14 & 2018 & 35 & 69 \\
\hline Optical radar & & 13 & 2017 & 55 & 104 \\
\hline Urban planning & & 13 & 2018 & 31 & 55 \\
\hline Aerial survey & & 10 & 2017 & 45 & 82 \\
\hline Motion planning & & 9 & 2017 & 25 & 40 \\
\hline
\end{tabular}

According to the number of co-occurrences, the most frequently keywords are: UAV (137 co-occurrences), Drones (95), Photogrammetry (40), Aircraft (38), Buildings (30), Remote sensing (27), Surveys (24), Data acquisition (21), and Thermography (imaging) (19) (Table 5). They are grouped into five clusters which can be identified by the different colours. The links in Figure 7 show co-occurrence relationships between all of them. The spatial arrangement of the clusters seems circular, they are equally distributed and there are no large distances between them that would reveal gaps in the literature. The blue and red clusters are the smallest graphically as indicated by the total link strength values of their nodes.

As expected, the most frequent keywords with the highest link strength and total link strength are those related to the main purpose of this research: UAV (85 and 641), Drones (82 and 488), Aircraft (64 and 201) and Buildings (64 and 173). The term UAS is less common, and RPAS does not seem to be used in the documents studied. The top keyword related to urbanism is Urban area with 14 co-occurrences. To facilitate the identification of the most common applications or techniques applied with UAVs in architecture and urban planning, the five clusters represented in the Figure 7 were analysed and labelled manually based on the observed keywords in that cluster. In each cluster the keywords are grouped according to their proximity in the literature demonstrating real relationships between the terms. This facilitated the identification of the techniques in relation to the most common fields of application of each one of them. For instance, in the green cluster, keywords related to data acquisition techniques for the generation of 3D reconstructions and mapping tasks appeared together. Consequently, this cluster was labelled as the Mapping and 3D modelling cluster. Similarly, the red, the blue, the yellow and the orange were labelled as Construction monitoring, Structural damage detection, Energy efficiency prospection and Urban remote sensing, respectively (Figure 8). The 235 articles in the 
database were filtered according to the frequency of these keywords and were classified into five groups to facilitate the literature review process (Figure 9).

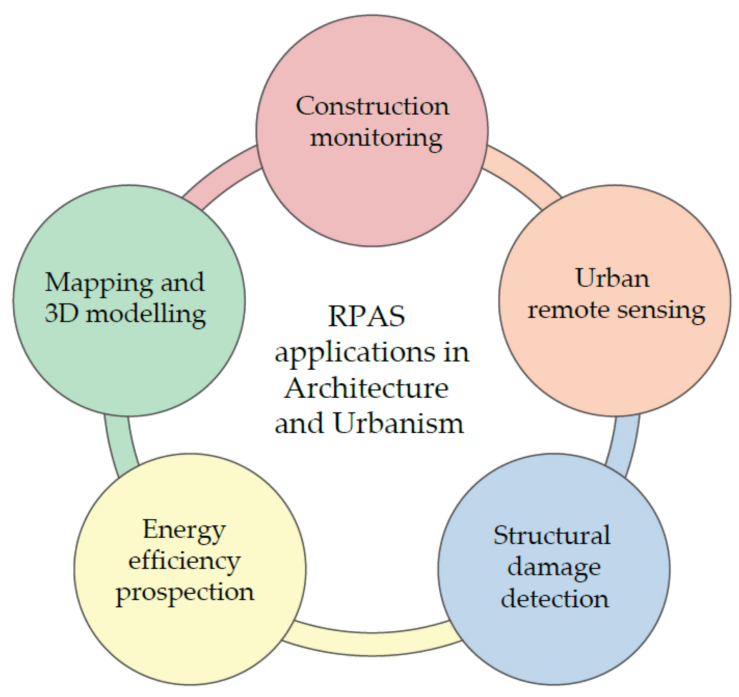

Figure 8. Fields of application and techniques based in clusters.

\section{Nㅇ OF DOCUMENTS}

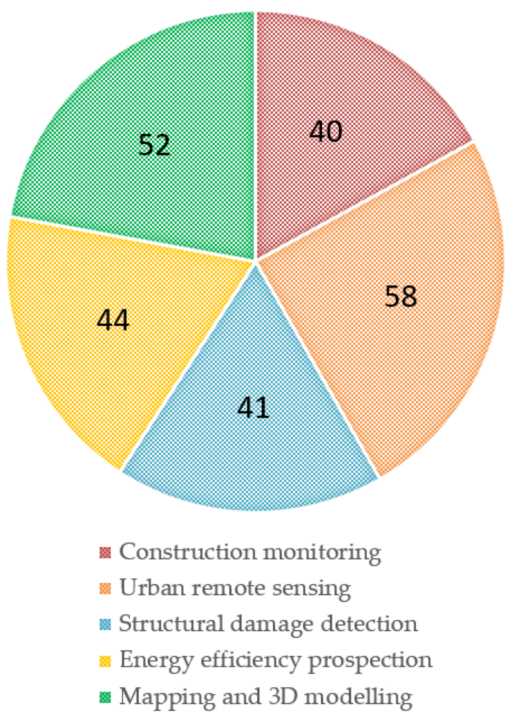

Figure 9. Number of documents per cluster.

\section{Critical Literature Review}

The areas of application identified in the scientometric analysis include different techniques related to the generation of 3D models, land mapping, construction site monitoring, building surveying to detect structural damage and energy losses and urban remote sensing. These techniques based on UAVs can be applied to buildings or public spaces from the design and construction processes when the project is initiated to the later stages of maintenance and inspection of the project during its life cycle.

In the initial process of designing a project, UAVs can be used to carry out remote sensing tasks to assess the feasibility of the project on an urban scale. Aerial images of the site can be combined with geographic information systems (GIS) to estimate parcel dimensions, accesses or altitude limitations. They can also be a useful source of information on the surrounding urban infrastructure, road inspections and water and electricity facilities [51]. The use of UAVs at this stage of the project gives the option to visualise the design, planning and organisation of the site before construction. 
At the beginning of the construction, UAVs as a data acquisition platform and as a measuring instrument are very attractive for topographical and terrain mapping applications $[1,4,52,53]$. Their geometric accuracy is better than traditional methods that usually incur a large error as demonstrated by Nikolakopoulos Konstantinos et al. (2017) who compared classical surveying, satellite images and aerial images from an unmanned aerial vehicle in an archaeological zone. They concluded that 3D models created by UAV imagery can achieve great accuracy and can replace reliable the in situ topographic survey [54]. The evaluation of aerial images is performed faster compared to images obtained from land [41]. They also provide more information than satellite images operating from a single vertical perspective [55]. Using photogrammetry techniques it is possible to acquire and visualise large quantities of images and videos which, if processed later by software, can provide orthophotos and digital surface models (DSM) [22], [56]. Sebastian Siebert et al. (2014) converted aerial images captured by an UAV into a three-dimensional model of a terrain using topography software [57]. In photogrammetry tasks are necessary to ensure a good overlap of images to capture the same points through several shots and to use a suitable visual detection device to capture high precision and quality photos covering the whole area to be examined. In this field, the most optimal payloads are vision stereo cameras and RGB cameras with depth sensors which are able to augment the conventional image with depth information (the distance to the sensor) necessary to generate 3D models [58].

These photogrammetry techniques are also used for site monitoring activities to increase the productivity of the construction process [59]. These inspections, which can be daily or weekly, make it possible to monitor progress, safety, quality and efficiency in the construction process [60]. Today, on-site data collection is traditionally more costly, time consuming and error prone (because it is a manual task) compared to the automated process of an aircraft [61]. One of the challenges of monitoring a construction site on a daily or weekly basis is the large amount of visual data that must be captured by the UAV and the computational load for further processing [12]. UAV images are taken by seconds at constant intervals which is a problem for the storage system if monitored on a daily or weekly basis. Kevin K. Han et al. (2017) estimated a visual data size that could reach 6 Terabytes if a construction site was inspected weekly for 2 years. They noted that to monitor a 70,000 $\mathrm{m}^{2}$ site, over 400,000 images would be needed over the lifetime of the project [46]. Facing this problem, filtering methods about semantic segmentation and image stitching techniques were applied to automatically recognize and filter out images containing important objects [47,62].

Another challenge is the variety of this type of scenario, which is constantly changing with temporary resources such as cranes and materials. UAVs are unable to track the location of dynamic objects on the construction site, limiting the safety inspection functions. In addition, a continuous process of capturing and processing images is required to provide performance information that must be communicated to the professionals who manage the construction project. It must be a fast process in order to get useful results in a real time change control [12]. For this reason, these types of tasks have been combined with building information modelling (BIM) systems which can provide preliminary information on the geometry and appearance of the views. BIM is a methodology for creating digital design simulations, managing all the information involved in an architectural project in a coordinated manner. These 3D models can be enriched with information acquired by UAVs about performance, time, costs, safety and productivity in construction sites. The combination of digital documentation acquired by an UAV together with BIM has demonstrated positive opportunities for the execution of daily work, short-term planning and communication and coordination between site teams [46,63]. Risk prevention and improvement of safety on construction sites is another field in which great results have been obtained using both techniques [48,49,64,65]. Jun Wang et al. (2015) presented a novel method to automatically identify fall and collapse hazards related to excavations on construction sites. Once the danger points were identified, the BIM was redesigned with an installation of safety equipment [48]. 
Once the work has been completed, the UAVs are still useful for monitoring and inspecting buildings in use. The usual photogrammetric techniques are applied to buildingsin-use to generate three-dimensional, orthophotos and orthomosaic models of facades and roofs affected by various pathologies [66-70]. The newest methodologies are applied to the analysis of the structural health of buildings in other complex environments where there is no GPS coverage [71]. Building monitoring to assess structural damage using UAVs takes on a key role in the field of remote sensing because of the rapid and effective response that these systems can provide to assess the ageing and deterioration of damaged buildings [72]. The main challenge of using images as a basis for the damage assessment process lies in the subjectivity of manual identification of damage from remote sensing. For example, damage can be seen on the envelope of a building that does not compromise its structural health. For this reason, new methods have been designed to extract more information from remote sensing data in a reliable and automated way [43]. Segmentation techniques and object-based approaches were subsequently applied to the three-dimensional models to detect vectors, shapes, textures and segments of the photographed buildings [42,73-75]. Methods such as object-based image analysis (OBIA) became popular because of their ability to incorporate image elements such as colours, sizes, shapes, textures and patterns in the segmentation process [76]. They were applied directly to images to extract more detailed characteristics of cracks and holes affecting structural elements of a building [77].

In the most recent publications, machine learning and deep learning are the most widely used methodologies $[78,79]$. The algorithms used in machine learning allow complex patterns to be identified through a large number of parameters. These algorithms parse data and constantly train them with the input of new variables to predict future scenarios and to acquire information automatically. Some techniques used in machine learning for this purpose were support vector machine (SVM) and random forest (RF) [80,81]. Deep learning uses neural network architectures such as convolutional neural networks (CNN). CNNs can learn the characteristics and representation of the pixel values of an image automatically and can give results in real time. They require less training if a sufficient number of starting datasets are assumed [82]. Diogo Duarte et al. (2018) and Francesco Nex et al. (2019) trained several CNNs with images of different resolutions obtaining more accurate results in building damage classification by merging several resolution layers $[43,44]$. These techniques optimize the process of identifying structural damage in images captured by UAVs.

The use of UAVs to assess urban damage in emergency situations after natural disasters such as floods [83], tornadoes and hurricanes [84] and earthquakes [85], has also proved to be very useful because of the feasibility of remote sensing for search and rescue tasks and estimates of material and economic losses [86].

In addition to high-resolution digital RGB cameras for aerial image acquisition, there are other types of payloads that allow data to be obtained by laser or radiation. The optical sensors which use range data like laser scanning technologies (for example, the LiDAR - Light Detection and Ranging) allow generate point clouds with 3D coordinates. The mapping is achieved through laser pulses towards the target and the measurement of its reflection with a sensor. The literature focused on the generation of point clouds and 3D models of buildings and terrains obtained more detailed results with laser scanning technology than with aerial photogrammetry techniques [68,87]. Young Hoon Jo et al. (2019) applied terrestrial laser scanning and photogrammetry techniques to cultural heritage buildings for classification, maintenance and surveillance. They compared both techniques and stated that laser scanning provides higher positional accuracy than photogrammetry [88]. These techniques has been commonly used for documentation and maintenance of historical heritage buildings [88-91].

Laser scanning technologies also proved their viability in urban planning tasks. High resolution remote sensing is an effective instrument for the production of three-dimensional digital models of cities that can be useful in the field for cadastral mapping and monitoring of public spaces in use $[92,93]$. Through the use of UAVs and LiDAR, precise urban 
maps were generated using 3D point clouds with segmentation techniques for the rapid identification of structures such as streets, facades, cars, trees, etc. [94]. Diagnostics of accessibility to urban environments were carried out by automatically detecting and classifying elements of urban land (roads, pavements, steps, risers and kerbs) based on 3D models processed with segmentation and machine learning techniques [95]. These techniques were supported by BIM to reduce calculation time in the creation of city information models (CIM) [96].

Some building sustainable new methodologies highlight the importance of monitoring the use period of the building to maintain their energy efficiency [97,98]. Advanced tools such as infrared cameras in UAVs allow professionals to perform energy inspections in buildings quickly and accurately, while reducing operational costs and minimising security risks. Using UAVs, energy inspections can be carried out to document the energy performance of buildings, visualise heat transfer using infrared images and create digital models through thermal patterns using 3D photogrammetry [99]. Thermal cameras capture the infrared energy emitted by the surface of an object [100]. This type of energy is absorbed and emitted by all materials and is directly related to the temperature of the object [101]. The most common indicator of anomalies, defects or failures in any physical element is the change in temperature, something easily identifiable with this type of cameras. The inspections carried out by thermography are complemented by terrestrial techniques such as blower door tests to detect infiltration/exfiltration regions and thermal bridges.

Energy audits in buildings can be carried out according to two methodologies: with active thermography, i.e., by means of an external stimulus such as an increase in the thermal gradient between the interior and exterior of the building to emphasise the contrast of thermal patterns; and with passive thermography, observing temperature changes in a normal state of the environment without any artificial stimulus [87]. Some authors proposed standardised and detailed procedures for energy inspections of buildings using UAVs [102,103]. Mattia Previtali et al. (2013) applied infrared thermography (IRT) to determine energy efficiency and detect defects such as thermal bridges and heat loss in a building. They demonstrated in their research that in addition to temperature, the surface geometry to be examined is a key point for a reliable evaluation of thermal efficiency [104]. It has been demonstrated that the evaluation of the geometry of the building envelope is fundamental for quantifying values such as thermal inertia and energy losses in building facades [58]. Infrared techniques have been widely used in the literature related to the energy efficiency of buildings. Juan Ortiz-Sanz et al. (2019) inspected a half-buried building using an infrared camera equipped on an UAV to acquire surface temperature data and complemented it with techniques carried out on land. Both cases proved to be effective in detecting thermal anomalies such as thermal bridges, air leaks, building singularities and humidity [105]. Julian Moore et al. (2018) conducted an aerial inspection to see the potential damage associated with heating, cooling and domestic hot water systems (HVAC) of a public building. They provided a simple and cost effective method to carry out timely inspections of installations confirming that early detection of defects and failures can prolong the life of this equipment [106]. Vincenzo Carletti et al. (2020) and Alvaro Huerta Herraiz et al. (2020) proposed novel methods for detecting faults in photovoltaic panels automatically during a routine inspection providing fast and efficient results [107,108].

Increasing attention to energy consumption issues is renewing interest in thermal remote sensing applications in urban areas [109]. Thermography can be used to carry out inspections of urban installations and to analyse temperature changes in urban soil. Yanfei Zhong et al. (2019) analysed the domestic hot water (DHW) pipeline leak detection process using remote sensing infrared images together with visible images and geographic information system (GIS) data to support the location of damaged pipes [110]. Joseph Naugthon et al. (2019) evaluated the spatial variability of soil temperatures, according to their use through thermal imaging of the UAVs captured at high resolutions [111]. The analysis of the thermal properties of urban materials is fundamental in determining the microclimate of a city and the energy balance of buildings. Thermography applied in UAVs 
allows the generation of maps of surface temperature distribution and material properties and can generate urban energy balance models [112]. In particular, the analysis of roof materiality, temperature, albedo and impermeability have proven to be key parameters in the quantification of the urban heat island effect [113,114]. Matias et al. (2020) examined the micro-meteorological scale in a Lisbon neighbourhood in order to evaluate the radiation balance of roofs, facades and other urban materials and their influence on air temperature. Using an UAV, they recorded the temperatures of these elements and concluded that these were directly due to incident solar radiation. They showed that the air in the streets less exposed to the prevailing wind direction of the city reached higher temperatures than the air in the streets more exposed to the prevailing wind direction [115]. Li et al. (2020) analysed temperature variation on six urban surfaces: water, tree canopy, grass, brick pavement, asphalt and marble in the city of Nanjing. Their results showed that surfaces of artificial origin released more sensible heat and that air humidity was negatively correlated with temperature variations [116]. Honjo et al. (2017) generated an orthogonal image of land surface temperature using thermal imaging and computer vision in the city of Tokyo. The experiment was repeated in two summers in 2007 and 2013 and the results showed an increase in land areas in 2007 that had been urbanised in 2013 [117]. The same conclusion was provided by Chen et al. (2017) in Taipei city where the diurnal variation of city temperature was proven to increase with the rate of urbanization [118].

Urban-scale thermography has also been widely used for the detection of residential roof heat losses and the identification of homes where energy savings can be made [119]. Ham et al. (2013) presented a novel automated method to calculate the cost of energy loss for building diagnostics by combining aerial thermography, manual thermography and an energy performance augmented reality (EPAR) model based on computational fluid dynamics (CFD). Based on the detected air leakage, heat losses and heat gains caused by poor insulation or air infiltration/extraction and the associated energy costs were automatically calculated [120]. In 2016, the ChoT project aimed to analyse the potential of aerial thermal imagery to produce large-scale datasets for energy efficiency and policy analysis in urban environments in the city of Bologna. The project was entitled "the Challenge of remote sensing Thermography as indicator of energy efficiency of buildings" (ChoT). It was funded by the Italian Ministry of Education, University and Research (MIUR) in the framework of the SIR 2014 (Scientific Independence of young Researchers) programme [121].

In addition, UAVs have demonstrated their feasibility in analysing and reducing various threats to human and environmental health such as air pollution in urban areas [112]. Emissions of volatile organic compounds from the petrochemical industry and vehicle exhaust gases contribute to the formation of ozone and organic aerosols. Some authors analysed air quality using an energy-efficient, real-time air quality monitoring system using aerial and ground-based detection [122-124].

The maximum exponent of urban energy efficiency is the smart city, a type of urban development based on sustainability. These are models of interconnected networks in the city that are fed back with large amounts of real time data [125]. Smart cities contain intelligent elements that allow measuring aspects related to the environment, quality of life, public safety and disaster management. To achieve these tasks, advanced collaborative technologies such as UAVs, machine learning and the Internet of Things (IoT) are required to lead to prudent management of natural resources [126]. An integrated technology of connected and autonomous vehicles was proposed for various uses such as the improvement of wireless capacity and coverage between cellular networks, urban video-surveillance of road and pedestrian traffic and transport of people and goods, among others [50,127]. In the next few years, it is expected that urban legislation will be relaxed to allow for largescale delivery of products by air. Currently, delivery companies are already registering patents for storage and loading systems for UAVs in the built environment $[6,128]$.

For further reading comprehension, Table 6 summarises the main applications and payloads identified by cluster. 
Table 6. Summary of main UAV applications and common UAV payload by cluster.

\begin{tabular}{|c|c|c|c|}
\hline Field of Application & Common UAV Payload & Application of UAV & References in Text \\
\hline \multirow[t]{2}{*}{$\begin{array}{c}\text { Green cluster: } \\
\text { Mapping and 3D modelling }\end{array}$} & \multirow[t]{2}{*}{$\begin{array}{c}\text { GPS-RTK module for } \\
\text { geo-referencing images, } \\
\text { camera gimbal, vision stereo } \\
\text { cameras, RGB-D digital } \\
\text { cameras, laser scanning } \\
\text { sensors (LiDAR) }\end{array}$} & $\begin{array}{l}\text { 3D Terrain digital } \\
\text { reconstruction }\end{array}$ & {$[1,4,52,53,57]$} \\
\hline & & $\begin{array}{l}\text { 3D Cultural heritage } \\
\text { modelling }\end{array}$ & {$[54,88-91]$} \\
\hline \multirow[t]{2}{*}{$\begin{array}{l}\text { Red cluster: } \\
\text { Construction monitoring }\end{array}$} & \multirow[t]{2}{*}{$\begin{array}{l}\text { GPS, camera gimbal, RGB } \\
\text { digital cameras, video-based } \\
\text { cameras, laser scanning } \\
\text { sensors (LiDAR) }\end{array}$} & $\begin{array}{l}\text { Construction site monitoring } \\
\text { in combination with Building } \\
\text { Information Model (BIM) }\end{array}$ & {$[12,46,60,63]$} \\
\hline & & Safety on construction & {$[64,65]$} \\
\hline \multirow[t]{2}{*}{$\begin{array}{l}\text { Blue cluster: } \\
\text { Structural damage detection }\end{array}$} & \multirow[t]{2}{*}{$\begin{array}{c}\text { GPS, camera gimbal, RGB } \\
\text { digital cameras, laser scanning } \\
\text { sensors (LiDAR) }\end{array}$} & Building damage mapping & {$[43,44,67-69,77]$} \\
\hline & & $\begin{array}{c}\text { Urban damage in emergency } \\
\text { situations }\end{array}$ & {$[66,83-86]$} \\
\hline \multirow[t]{2}{*}{$\begin{array}{l}\text { Yellow cluster: } \\
\text { Energy efficiency } \\
\text { prospection }\end{array}$} & \multirow[t]{2}{*}{$\begin{array}{l}\text { GPS, camera gimbal, RGB } \\
\text { digital cameras, thermal } \\
\text { imaging infrared cameras }\end{array}$} & Building energy inspection & {$[99,103-106,120]$} \\
\hline & & Photovoltaic panels inspection & {$[107,108]$} \\
\hline \multirow[t]{6}{*}{$\begin{array}{l}\text { Orange cluster: } \\
\text { Urban remote sensing }\end{array}$} & \multirow[t]{6}{*}{$\begin{array}{l}\text { GPS, camera gimbal, RGB } \\
\text { digital cameras, video.based } \\
\text { cameras, laser scanning } \\
\text { sensors (LiDAR), thermal } \\
\text { imaging infrared cameras }\end{array}$} & 3D City digital reconstruction & {$[95,96]$} \\
\hline & & Urban thermal monitoring & {$[111-117,121]$} \\
\hline & & $\begin{array}{l}\text { Urban energy system } \\
\text { inspection }\end{array}$ & [110] \\
\hline & & Air quality control & [122-124] \\
\hline & & Smart city & {$[6,50,125-127]$} \\
\hline & & Cadastral mapping & [92] \\
\hline
\end{tabular}

\section{Conclusions}

The use of UAVs is becoming more frequent in applications related to architecture and urbanism. The revolution in unmanned aerial vehicles offers new opportunities in different applications due to the reduction of risks and lower costs involved in this type of platform. This paper has provided a critical review of the literature surrounding the applications of UAVs in architecture and urbanism identifying hot topics and weak points that needs to be developed. For this purpose, a scientometric analysis of a base of 235 academic articles was carried out, from which the appropriate structure was obtained to perform a bibliometric analysis afterwards. This research has demonstrated the feasibility of conducting scientific mapping using the bibliographic database Scopus ${ }^{\mathrm{TM}}$ and the scientometric software VOSviewer ${ }^{\mathrm{TM}}$ in a large body of literature to provide interesting information and identify important trends.

The scientometric analysis carried out prior to the literature review allowed for the analysis of factors such as the most prolific authors, countries and documents in this area of knowledge. After carrying out several co-authoring, citation and bibliographic coupling analyses of each unit of analysis, different results were obtained based on the number 
of documents and the number of citations. For example, authors with more published documents do not accumulate more citations and vice versa. However, a relationship was observed between the number of citations and the average year of publication. The most cited papers were published in very early stages, making them a source of guidance and reference for other researchers. European countries proved to be the pioneers in researching the applications of UAVs in architecture and urbanism due to their high number of citations, although other Asian and American countries have shown greater productivity and exceeded their numbers in recent years. Certain gaps in the literature were also observed such as the lack of collaboration between the most prolific authors from different continents. It should be mentioned that the lack of collaboration between authors from different universities and different countries affects negatively the dissemination of published articles.

The different application areas and techniques most frequently used in this research field were identified based on the most frequently cited journals and documents and the most frequent keywords in the literature database. The analysis of the most frequently cited journals and documents was useful to identify the fields of study in a general area that was delimited through the analysis of the most frequent keywords in: generation of 3D models, land mapping, construction site monitoring, building surveying to detect structural damage and energy losses and urban remote sensing. The large body of literature was synthesised and the documents were filtered according to the area of application and the techniques found in order to optimise the literature review process that followed the lines drawn by the keywords.

The literature review showed that UAVs provide a useful multi-tasking tool at any stage of a construction project. First, the different techniques applied in the design and construction process of a project were analysed, such as the use of photogrammetry in urban spaces, land and construction sites to study the viability of a project or to monitor a construction site. Then, the tasks corresponding to the maintenance and inspection stages of a building or public space during its useful life were studied using other techniques. Methods based on laser scanning, infrared and post-processing techniques were used to generate three-dimensional models of cities or heritage monuments, and to carry out energy analysis or damage assessment on an urban and building scale. In each of the application areas, research trends and future perspectives were discussed.

Regarding the limitations of the research, it is important to highlight that any review based on a data-driven approach is highly dependent on the quality of the data collected [129]. Although a thorough article filtering process was carried out, it cannot be assured that all relevant articles were collected because: (i) other interesting non-English language publications were not taken into account, (ii) the literature searches were organised by logical combinations of words related to the topic, but not all synonyms or alternative terms that other researchers may have used in their work could be collected, (iii) the Scopus ${ }^{\mathrm{TM}}$ database finds the searched terms in the title, abstract and keywords, but does not analyse the full text of the publication. For the definition of the application fields, VOSviewer ${ }^{\mathrm{TM}}$ grouped the keywords according to their co-occurrence by clusters and then they were manually labelled according to the authors' criteria. These could be called by another name by other experts. In addition, some keywords are likely to belong to more than one cluster, despite being marked in a single colour, especially when the topics are related to each other. For example, the word Defects is grouped in the Energy efficiency prospection cluster but would also be linked to the Structural damage detection cluster.

Further studies are needed to define best practices for the current and future integration of UAVs in architecture and urban planning. Some of the research areas identified present certain challenges that, if solved in the coming years, could have great potential. UAVs have demonstrated certain limitations in their positional inaccuracy despite the use of GPS and IMU components. Improved aircraft control, the use of anti-collision sensors and new GPS replacement devices will offer a solution to the problem of data acquisition inside buildings with energy or structural pathologies. Many cases of UAVs 
used for the development of high-quality 3D models have been documented (civil works, mapping, buildings, public spaces, neighbourhoods, cities...) but there are few examples describing an established workflow or a common methodology for image post-processing. The development of new methodologies for image processing and automatic identification of key elements of the scene will allow the extraction of useful information with significant time savings (an essential factor in tasks requiring continuous data collection and real-time assessment). The integration of UAVs with other recent technological innovations such as BIM, photo/videogrammetry, virtual and augmented reality, big data, IoT, 5G technology, artificial intelligence and machine learning predictive analysis will offer multiple opportunities for the application of these aircraft at city scale, a field where more research has been registered and with a greater projection in the coming years.

The results shown in this research, both the described challenges and opportunities, are expected to be useful to building designers, construction companies, engineering developers, environmental policymakers and the scientific community in the continued development and expansion of the UAV market for use in the field of architecture and urbanism.

Author Contributions: S.G.M., conceived the idea and experimentation, checked the manuscript and carried out the revision; M.V.R., wrote the article and made the corrections; A.S.C., carried out the experimentation; J.M.A.M., supervised and reviewed all work and the manuscript. All authors have read and agreed to the published version of the manuscript.

Funding: This work has been funded by the Research Center for Technology, Energy and Sustainability (CITES) at the University of Huelva.

Institutional Review Board Statement: Not applicable.

Informed Consent Statement: Not applicable.

Data Availability Statement: Not applicable.

Conflicts of Interest: The authors declare no conflict of interest.

\section{References}

1. Siebert, S.; Teizer, J. Mobile 3D mapping for surveying earthwork projects using an Unmanned Aerial Vehicle (UAV) system. Autom. Constr. 2014, 41,1-14. [CrossRef]

2. Verykokou, S.; Ioannidis, C.; Athanasiou, G.; Doulamis, N.; Amditis, A. 3D reconstruction of disaster scenes for urban search and rescue. Multimed. Tools Appl. 2018, 77, 9691-9717. [CrossRef]

3. Hausamann, D.; Zirnig, W.; Schreier, G.; Strobl, P. Monitoring of gas pipelines-A civil UAV application. Aircr. Eng. Aerosp. Technol. 2005, 77, 352-360. [CrossRef]

4. Álvares, J.S.; Costa, D.B.; Melo, R.R.S. De Exploratory study of using unmanned aerial system imagery for construction site 3D mapping. Constr. Innov. 2018, 18, 301-320. [CrossRef]

5. Sarabia, R.; Aquino, A.; Ponce, J.M.; López, G.; Andújar, J.M. Automated identification of crop tree crowns from uav multispectral imagery by means of morphological image analysis. Remote Sens. 2020, 12, 748. [CrossRef]

6. Aurambout, J.P.; Gkoumas, K.; Ciuffo, B. Last mile delivery by drones: An estimation of viable market potential and access to citizens across European cities. Eur. Transp. Res. Rev. 2019, 11, 30. [CrossRef]

7. Li, M.; Zhen, L.; Wang, S.; Lv, W.; Qu, X. Unmanned aerial vehicle scheduling problem for traffic monitoring. Comput. Ind. Eng. 2018, 122, 15-23. [CrossRef]

8. Kim, H.; Mokdad, L.; Ben-Othman, J. Designing UAV Surveillance Frameworks for Smart City and Extensive Ocean with Differential Perspectives. IEEE Commun. Mag. 2018, 56, 98-104. [CrossRef]

9. Burke, P.J. Demonstration and application of diffusive and ballistic wave propagation for drone-to-ground and drone-to-drone wireless communications. Sci. Rep. 2020, 10, 1-12. [CrossRef]

10. Shakhatreh, H.; Sawalmeh, A.H.; Al-Fuqaha, A.; Dou, Z.; Almaita, E.; Khalil, I.; Othman, N.S.; Khreishah, A.; Guizani, M. Unmanned Aerial Vehicles (UAVs): A Survey on Civil Applications and Key Research Challenges. IEEE Access 2019, 7, 4857248634. [CrossRef]

11. Albeaino, G.; Gheisari, M.; Franz, B.W. A systematic review of unmanned aerial vehicle application areas and technologies in the AEC domain. J. Inf. Technol. Constr. 2019, 24, 381-405. [CrossRef]

12. Ham, Y.; Han, K.K.; Lin, J.J.; Golparvar-Fard, M. Visual monitoring of civil infrastructure systems via camera-equipped Unmanned Aerial Vehicles (UAVs): A review of related works. Vis. Eng. 2016, 4, Article. [CrossRef]

13. Golizadeh, H.; Hosseini, M.R.; Edwards, D.J.; Abrishami, S.; Taghavi, N.; Banihashemi, S. Barriers to adoption of RPAs on construction projects: A task-technology fit perspective. Constr. Innov. 2019, 19, 149-169. [CrossRef] 
14. Chen, C.; Dubin, R.; Schultz, T. Science Mapping. In Encyclopedia of Information Science and Technology, 3rd ed.; IGI Global: Hampshire, UK, 2014; pp. 4171-4184. [CrossRef]

15. Cobo, M.J.; López-Herrera, A.G.; Herrera-Viedma, E.; Herrera, F. Science Mapping Software Tools: Review, Analysis, and Cooperative Study Among Tools. J. Am. Soc. Inf. Sci. Technol. 2011, 62, 1382-1402. [CrossRef]

16. Small, H. Update on science mapping: Creating large document spaces. Scientometrics 1997, 38, 275-293. [CrossRef]

17. Morris, S.A.; Van Der Veer Martens, B. Mapping research specialties. Annu. Rev. Inf. Sci. Technol. 2008, 42, 213-295. [CrossRef]

18. Börner, K.; Chen, C.; Boyack, K.W. Visualizing knowledge domains. Annu. Rev. Inf. Sci. Technol. 2003, 37, 179-255. [CrossRef]

19. Su, H.N.; Lee, P.C. Mapping knowledge structure by keyword co-occurrence: A first look at journal papers in Technology Foresight. Scientometrics 2010, 85, 65-79. [CrossRef]

20. Zhou, S.; Gheisari, M. Unmanned aerial system applications in construction: A systematic review. Constr. Innov. 2018, 18, 453-468. [CrossRef]

21. Greenwood, W.W.; Lynch, J.P.; Zekkos, D. Applications of UAVs in Civil Infrastructure. J. Infrastruct. Syst. 2019, 25, 04019002. [CrossRef]

22. Liu, P.; Chen, A.Y.; Huang, Y.N.; Han, J.Y.; Lai, J.S.; Kang, S.C.; Wu, T.H.; Wen, M.C.; Tsai, M.H. A review of rotorcraft unmanned aerial vehicle (UAV) developments and applications in civil engineering. Smart Struct. Syst. 2014, 13, 1065-1094. [CrossRef]

23. Hosseini, M.R.; Martek, I.; Zavadskas, E.K.; Aibinu, A.A.; Arashpour, M.; Chileshe, N. Critical evaluation of off-site construction research: A Scientometric analysis. Autom. Constr. 2018, 87, 235-247. [CrossRef]

24. Chen, C. Science Mapping: A Systematic Review of the Literature. J. Data Inf. Sci. 2017, 2, 1-40. [CrossRef]

25. Falagas, M.E.; Pitsouni, E.I.; Malietzis, G.A.; Pappas, G. Comparison of PubMed, Scopus, Web of Science, and Google Scholar: Strengths and weaknesses. FASEB J. 2008, 22, 338-342. [CrossRef] [PubMed]

26. Archambault, É.; Campbell, D.; Gingras, Y.; Larivière, V. Comparing bibliometric statistics obtained from the web of science and scopus. J. Am. Soc. Inf. Sci. Technol. 2009, 60, 1320-1326. [CrossRef]

27. Zhao, X.; Zuo, J.; Wu, G.; Huang, C. A bibliometric review of green building research 2000-2016. Archit. Sci. Rev. 2019, 62, 74-88. [CrossRef]

28. Meho, L.I.; Rogers, Y. Citation Counting, Citation Ranking, and h-Index of Human-Computer Interaction Researchers: A Comparison of Scopus and Web of Science. J. Am. Soc. Inf. Sci. Technol. 2008, 59, 1711-1726. [CrossRef]

29. Scopus. Available online: https://scopus.com (accessed on 1 September 2020).

30. Börner, K.; Huang, W.; Linnemeier, M.; Duhon, R.J.; Phillips, P.; Ma, N.; Zoss, A.M.; Guo, H.; Price, M.A. Rete-netzwerk-red: Analyzing and visualizing scholarly networks using the Network Workbench Tool. Scientometrics 2010, 83, 863-876. [CrossRef]

31. Van Eck, N.J.; Waltman, L. Visualizing Bibliometric Networks. Meas. Sch. Impact 2014, 1, 285-320. [CrossRef]

32. Van Eck, N.J.; Waltman, L. Software survey: VOSviewer, a computer program for bibliometric mapping. Scientometrics 2010, 84, 523-538. [CrossRef] [PubMed]

33. Garrigos-Simon, F.J.; Narangajavana-Kaosiri, Y.; Lengua-Lengua, I. Tourism and sustainability: A bibliometric and visualization analysis. Sustainabilty 2018, 10, 1976. [CrossRef]

34. Gizzi, F.T.; Leucci, G. Global Research Patterns on Ground Penetrating Radar (GPR). Surv. Geophys. 2018, 39, 1039-1068. [CrossRef]

35. Colares, G.S.; Dell'Osbel, N.; Wiesel, P.G.; Oliveira, G.A.; Lemos, P.H.Z.; da Silva, F.P.; Lutterbeck, C.A.; Kist, L.T.; Machado, Ê.L. Floating treatment wetlands: A review and bibliometric analysis. Sci. Total Environ. 2020, 714, 136776. [CrossRef] [PubMed]

36. Niñerola, A.; Sánchez-Rebull, M.V.; Hernández-Lara, A.B. Tourism research on sustainability: A bibliometric analysis. Sustainabilty 2019, 11, 1377. [CrossRef]

37. Gough, M.; Santos, S.F.; Javadi, M.; Castro, R.; Catalão, J.P.S. Prosumer flexibility: A comprehensive state-of-the-art review and scientometric analysis. Energies 2020, 13, 2710. [CrossRef]

38. van Eck, N.J.; Waltman, L. Citation-based clustering of publications using CitNetExplorer and VOSviewer. Scientometrics 2017, 111, 1053-1070. [CrossRef] [PubMed]

39. VOSviewer. Available online: https://vosviewer.com (accessed on 5 November 2020).

40. Perianes-Rodriguez, A.; Waltman, L.; van Eck, N.J. Constructing bibliometric networks: A comparison between full and fractional counting. J. Informetr. 2016, 10, 1178-1195. [CrossRef]

41. Fernandez Galarreta, J.; Kerle, N.; Gerke, M. UAV-based urban structural damage assessment using object-based image analysis and semantic reasoning. Nat. Hazards Earth Syst. Sci. 2015, 15, 1087-1101. [CrossRef]

42. Vetrivel, A.; Gerke, M.; Kerle, N.; Vosselman, G. Identification of damage in buildings based on gaps in 3D point clouds from very high resolution oblique airborne images. ISPRS J. Photogramm. Remote Sens. 2015, 105, 61-78. [CrossRef]

43. Duarte, D.; Nex, F.; Kerle, N.; Vosselman, G. Multi-resolution feature fusion for image classification of building damages with convolutional neural networks. Remote Sens. 2018, 10, 1636. [CrossRef]

44. Nex, F.; Duarte, D.; Tonolo, F.G.; Kerle, N. Structural building damage detection with deep learning: Assessment of a state-of-theart CNN in operational conditions. Remote Sens. 2019, 11, 2765. [CrossRef]

45. Kerle, N.; Nex, F.; Gerke, M.; Duarte, D.; Vetrivel, A. UAV-based structural damage mapping: A review. ISPRS Int. J. Geo-Information 2019, 9, 14. [CrossRef]

46. Han, K.K.; Golparvar-Fard, M. Potential of big visual data and building information modeling for construction performance analytics: An exploratory study. Autom. Constr. 2017, 73, 184-198. [CrossRef] 
47. Ham, Y.; Kamari, M. Automated content-based filtering for enhanced vision-based documentation in construction toward exploiting big visual data from drones. Autom. Constr. 2019, 105, 102831. [CrossRef]

48. Wang, J.; Zhang, S.; Teizer, J. Geotechnical and safety protective equipment planning using range point cloud data and rule checking in building information modeling. Autom. Constr. 2015, 49, 250-261. [CrossRef]

49. Golovina, O.; Teizer, J.; Pradhananga, N. Heat map generation for predictive safety planning: Preventing struck-by and near miss interactions between workers-on-foot and construction equipment. Autom. Constr. 2016, 71, 99-115. [CrossRef]

50. Menouar, H.; Guvenc, I.; Akkaya, K.; Uluagac, A.S.; Kadri, A.; Tuncer, A. UAV-enabled intelligent transportation systems for the smart city: Applications and challenges. IEEE Commun. Mag. 2017, 55, 22-28. [CrossRef]

51. Zhou, Z.; Irizarry, J.; Lu, Y. A Multidimensional Framework for Unmanned Aerial System Applications in Construction Project Management. J. Manag. Eng. 2018, 34, 04018004. [CrossRef]

52. Schmid, K.; Hirschmüller, H.; Dömel, A.; Grixa, I.; Suppa, M.; Hirzinger, G. View planning for multi-view stereo 3D Reconstruction using an autonomous multicopter. J. Intell. Robot. Syst. Theory Appl. 2012, 65, 309-323. [CrossRef]

53. Torres, M.; Pelta, D.A.; Verdegay, J.L.; Torres, J.C. Coverage path planning with unmanned aerial vehicles for 3D terrain reconstruction. Expert Syst. Appl. 2016, 55, 441-451. [CrossRef]

54. Nikolakopoulos, K.G.; Soura, K.; Koukouvelas, I.K.; Argyropoulos, N.G. UAV vs classical aerial photogrammetry for archaeological studies. J. Archaeol. Sci. Rep. 2017, 14, 758-773. [CrossRef]

55. Turner, D.; Lucieer, A.; Wallace, L. Direct georeferencing of ultrahigh-resolution UAV imagery. IEEE Trans. Geosci. Remote Sens. 2014, 52, 2738-2745. [CrossRef]

56. Nex, F.; Remondino, F. UAV for 3D mapping applications: A review. Appl. Geomat. 2014, 6, 1-15. [CrossRef]

57. Bemis, S.P.; Micklethwaite, S.; Turner, D.; James, M.R.; Akciz, S.; Thiele, S.T.; Bangash, H.A. Ground-based and UAV-Based photogrammetry: A multi-scale, high-resolution mapping tool for structural geology and paleoseismology. J. Struct. Geol. 2014, 69, 163-178. [CrossRef]

58. Roca, D.; Lagüela, S.; Díaz-Vilariño, L.; Armesto, J.; Arias, P. Low-cost aerial unit for outdoor inspection of building façades. Autom. Constr. 2013, 36, 128-135. [CrossRef]

59. Chen, Q.; García de Soto, B.; Adey, B.T. Construction automation: Research areas, industry concerns and suggestions for advancement. Autom. Constr. 2018, 94, 22-38. [CrossRef]

60. Wang, J.; Sun, W.; Shou, W.; Wang, X.; Wu, C.; Chong, H.Y.; Liu, Y.; Sun, C. Integrating BIM and LiDAR for Real-Time Construction Quality Control. J. Intell. Robot. Syst. Theory Appl. 2015, 79, 417-432. [CrossRef]

61. Asadi, K.; Kalkunte Suresh, A.; Ender, A.; Gotad, S.; Maniyar, S.; Anand, S.; Noghabaei, M.; Han, K.; Lobaton, E.; Wu, T. An integrated UGV-UAV system for construction site data collection. Autom. Constr. 2020, 112, 103068. [CrossRef]

62. Bang, S.; Kim, H.; Kim, H. UAV-based automatic generation of high-resolution panorama at a construction site with a focus on preprocessing for image stitching. Autom. Constr. 2017, 84, 70-80. [CrossRef]

63. Kim, S.; Kim, S.; Lee, D.E. Sustainable application of hybrid point cloud and BIM method for tracking construction progress. Sustainability 2020, 12, 4106. [CrossRef]

64. Kim, S.; Irizarry, J.; Costa, D.B. Field Test-Based UAS Operational Procedures and Considerations for Construction Safety Management: A Qualitative Exploratory Study. Int. J. Civ. Eng. 2020, 18, 919-933. [CrossRef]

65. Guo, H.; Yu, Y.; Skitmore, M. Visualization technology-based construction safety management: A review. Autom. Constr. 2017, 73, 135-144. [CrossRef]

66. Dominici, D.; Alicandro, M.; Massimi, V. UAV photogrammetry in the post-earthquake scenario: Case studies in L'Aquila. Geomatics, Nat. Hazards Risk 2017, 8, 87-103. [CrossRef]

67. Choi, J.; Yeum, C.M.; Dyke, S.J.; Jahanshahi, M.R. Computer-aided approach for rapid post-event visual evaluation of a building Façade. Sensors 2018, 18, 3017. [CrossRef]

68. Russo, M.; Carnevali, L.; Russo, V.; Savastano, D.; Taddia, Y. Modeling and deterioration mapping of façades in historical urban context by close-range ultra-lightweight UAVs photogrammetry. Int. J. Archit. Herit. 2019, 13, 549-568. [CrossRef]

69. Massimiliano, P. Image-based methods for metric surveys of buildings using modern optical sensors and tools: From 2D approach to 3D and vice versa. Int. J. Civ. Eng. Technol. 2018, 9, 729-745.

70. Wang, J.A.; Ma, H.T.; Wang, C.M.; He, Y.J. Fast 3D reconstruction method based on UAV photography. ETRI J. 2018, 40, 788-793. [CrossRef]

71. Kang, D.; Cha, Y.J. Autonomous UAVs for Structural Health Monitoring Using Deep Learning and an Ultrasonic Beacon System with Geo-Tagging. Comput. Civ. Infrastruct. Eng. 2018, 33, 885-902. [CrossRef]

72. Barrington, L.; Ghosh, S.; Greene, M.; Har-Noy, S.; Berger, J.; Gill, S.; Lin, A.Y.M.; Huyck, C. Crowdsourcing earthquake damage assessment using remote sensing imagery. Ann. Geophys. 2011, 54, 680-687. [CrossRef]

73. Malihi, S.; Zoej, M.J.V.; Hahn, M. Large-scale accurate reconstruction of buildings employing point clouds generated from UAV imagery. Remote Sens. 2018, 10, 1148. [CrossRef]

74. Yan, Y.; Gao, F.; Deng, S.; Su, N. A hierarchical building segmentation in digital surface models for 3D reconstruction. Sensors 2017, 17, 222. [CrossRef]

75. Li, S.; Tang, H.; He, S.; Shu, Y.; Mao, T.; Li, J.; Xu, Z. Unsupervised Detection of Earthquake-Triggered Roof-Holes from UAV Images Using Joint Color and Shape Features. IEEE Geosci. Remote Sens. Lett. 2015, 12, 1823-1827. [CrossRef] 
76. Hay, G.J.; Castilla, G. Geographic Object-Based Image Analysis (GEOBIA): A New Name for a New Discipline; Lecture Notes in Geoinformation and Cartography; Chapter: 1.4; Springer: Berlin/Heidelberg, Germany, 2008; pp. 75-89. [CrossRef]

77. Zeng, T.; Yang, W.N.; Li, X.D. Seismic damage information extent about the buildings based on low-altitude remote sensing images of mianzu quake-stricken areas. Appl. Mech. Mater. 2012, 105-107, 1889-1893. [CrossRef]

78. Perez, H.; Tah, J.H.M.; Mosavi, A. Deep Learning for Detecting Building Defects Using Convolutional Neural Networks. Sensors 2019, 19, 3556. [CrossRef]

79. Xiong, C.; Li, Q.; Lu, X. Automated regional seismic damage assessment of buildings using an unmanned aerial vehicle and a convolutional neural network. Autom. Constr. 2020, 109, 102994. [CrossRef]

80. $\mathrm{Xu}, \mathrm{Z}$.; $\mathrm{Wu}, \mathrm{L} . ; \mathrm{Zhang}$, Z. Use of active learning for earthquake damage mapping from UAV photogrammetric point clouds. Int. J. Remote Sens. 2018, 39, 5568-5595. [CrossRef]

81. Gong, L.; Wang, C.; Wu, F.; Zhang, J.; Zhang, H.; Li, Q. Earthquake-induced building damage detection with post-event sub-meter VHR terrasar-X staring spotlight imagery. Remote Sens. 2016, 8, 887. [CrossRef]

82. Jiang, S.; Zhang, J. Real-time crack assessment using deep neural networks with wall-climbing unmanned aerial system. Comput. Civ. Infrastruct. Eng. 2020, 35, 549-564. [CrossRef]

83. Jiménez-Jiménez, S.I.; Ojeda-Bustamante, W.; Ontiveros-Capurata, R.E.; de Jesús Marcial-Pablo, M. Rapid urban flood damage assessment using high resolution remote sensing data and an object-based approach. Geomat. Nat. Hazards Risk 2020, 11, 906-927. [CrossRef]

84. Kakooei, M.; Baleghi, Y. Fusion of satellite, aircraft, and UAV data for automatic disaster damage assessment. Int. J. Remote Sens. 2017, 38, 2511-2534. [CrossRef]

85. Grazzini, A.; Chiabrando, F.; Foti, S.; Sammartano, G.; Spanò, A. A Multidisciplinary Study on the Seismic Vulnerability of St. Agostino Church in Amatrice following the 2016 Seismic Sequence. Int. J. Archit. Herit. 2020, 14, 885-902. [CrossRef]

86. Ehrlich, D.; Guo, H.D.; Molch, K.; Ma, J.W.; Pesaresi, M. Identifying damage caused by the 2008 wenchuan earthquake from VHR remote sensing data. Int. J. Digit. Earth 2009, 2, 309-326. [CrossRef]

87. Rakha, T.; Gorodetsky, A. Review of Unmanned Aerial System (UAS) applications in the built environment: Towards automated building inspection procedures using drones. Autom. Constr. 2018, 93, 252-264. [CrossRef]

88. Hoon, Y.J.; Hong, S. Three-dimensional digital documentation of cultural heritage site based on the convergence of terrestrial laser scanning and unmanned aerial vehicle photogrammetry. ISPRS Int. J. Geo-Inf. 2019, 8, 53. [CrossRef]

89. Fernández-Lozano, J.; Gutiérrez-Alonso, G. Improving archaeological prospection using localized UAVs assisted photogrammetry: An example from the Roman Gold District of the Eria River Valley (NW Spain). J. Archaeol. Sci. Rep. 2016, 5, 509-520. [CrossRef]

90. Marques, L.; Tenedório, J.A.; Burns, M.; Româo, T.; Birra, F.; Marques, J.; Pires, A. Cultural heritage 3D modelling and visualisation within an augmented reality environment, based on geographic information technologies and mobile platforms. Archit. City Environ. 2017, 11, 117-136. [CrossRef]

91. Xu, Z.; Wu, L.; Shen, Y.; Li, F.; Wang, Q.; Wang, R. Tridimensional reconstruction applied to cultural heritage with the use of camera-equipped UAV and terrestrial laser scanner. Remote Sens. 2014, 6, 10413-10434. [CrossRef]

92. Erenoglu, R.C.; Erenoglu, O.; Arslan, N. Accuracy assessment of low cost UAV based city modelling for urban planning. Teh. Vjesn. 2018, 25, 1708-1714. [CrossRef]

93. Crommelinck, S.; Bennett, R.; Gerke, M.; Nex, F.; Yang, M.Y.; Vosselman, G. Review of automatic feature extraction from high-resolution optical sensor data for UAV-based cadastral mapping. Remote Sens. 2016, 8, 689. [CrossRef]

94. Babahajiani, P.; Fan, L.; Kämäräinen, J.K.; Gabbouj, M. Urban 3D segmentation and modelling from street view images and LiDAR point clouds. Mach. Vis. Appl. 2017, 28, 679-694. [CrossRef]

95. Balado, J.; Díaz-Vilariño, L.; Arias, P.; González-Jorge, H. Automatic classification of urban ground elements from mobile laser scanning data. Autom. Constr. 2018, 86, 226-239. [CrossRef]

96. Chen, K.; Lu, W.; Xue, F.; Tang, P.; Li, L.H. Automatic building information model reconstruction in high-density urban areas: Augmenting multi-source data with architectural knowledge. Autom. Constr. 2018, 93, 22-34. [CrossRef]

97. Melgar, S.G.; Bohórquez, M.Á.M.; Márquez, J.M.A. UhuMEB: Design, construction, and management methodology of minimum energy buildings in subtropical climates. Energies 2018, 11, 2745. [CrossRef]

98. Gómez Melgar, S.; Martínez Bohórquez, M.Á.; Andújar Márquez, J.M. uhuMEBr: Energy Refurbishment of Existing Buildings in Subtropical Climates to Become Minimum Energy Buildings. Energies 2020, 13, 1204. [CrossRef]

99. Sfarra, S.; Cicone, A.; Yousefi, B.; Ibarra-Castanedo, C.; Perilli, S.; Maldague, X. Improving the detection of thermal bridges in buildings via on-site infrared thermography: The potentialities of innovative mathematical tools. Energy Build. 2019, 182, 159-171. [CrossRef]

100. Barreira, E.; de Freitas, V.P. Evaluation of building materials using infrared thermography. Constr. Build. Mater. 2007, 21, 218-224. [CrossRef]

101. Clark, M.R.; McCann, D.M.; Forde, M.C. Application of infrared thermography to the non-destructive testing of concrete and masonry bridges. NDT E Int. 2003, 36, 265-275. [CrossRef]

102. Nardi, I.; Lucchi, E.; de Rubeis, T.; Ambrosini, D. Quantification of heat energy losses through the building envelope: A state-ofthe-art analysis with critical and comprehensive review on infrared thermography. Build. Environ. 2018, 146, 190-205. [CrossRef]

103. Ficapal, A.; Mutis, I. Framework for the detection, diagnosis, and evaluation of thermal bridges using infrared thermography and unmanned aerial vehicles. Buildings 2019, 9, 179. [CrossRef] 
104. Previtali, M.; Barazzetti, L.; Brumana, R.; Roncoroni, F. Thermographic analysis from uav platforms for energy efficiency retrofit applications. J. Mob. Multimed. 2013, 9, 66-82.

105. Ortiz-Sanz, J.; Gil-Docampo, M.; Arza-García, M.; Cañas-Guerrero, I. IR thermography from UAVs to monitor thermal anomalies in the envelopes of traditional wine cellars: Field test. Remote Sens. 2019, 11, 1424. [CrossRef]

106. Moore, J.; Tadinada, H.; Kirsche, K.; Perry, J.; Remen, F.; Tse, Z.T.H. Facility inspection using UAVs: A case study in the University of Georgia campus. Int. J. Remote Sens. 2018, 39, 7189-7200. [CrossRef]

107. Carletti, V.; Greco, A.; Saggese, A.; Vento, M. An intelligent flying system for automatic detection of faults in photovoltaic plants. J. Ambient Intell. Humaniz. Comput. 2020, 11, 2027-2040. [CrossRef]

108. Huerta Herraiz, Á.; Pliego Marugán, A.; García Márquez, F.P. Photovoltaic plant condition monitoring using thermal images analysis by convolutional neural network-based structure. Renew. Energy 2020, 153, 334-348. [CrossRef]

109. Bitelli, G.; Conte, P.; Csoknyai, T.; Franci, F.; Girelli, V.A.; Mandanici, E. Aerial thermography for energetic modelling of cities. Remote Sens. 2015, 7, 2152-2170. [CrossRef]

110. Zhong, Y.; Xu, Y.; Wang, X.; Jia, T.; Xia, G.; Ma, A.; Zhang, L. Pipeline leakage detection for district heating systems using multisource data in mid- and high-latitude regions. ISPRS J. Photogramm. Remote Sens. 2019, 151, 207-222. [CrossRef]

111. Naughton, J.; McDonald, W. Evaluating the variability of urban land surface temperatures using drone observations. Remote Sens. 2019, 11, 1722. [CrossRef]

112. Gaitani, N.; Burud, I.; Thiis, T.; Santamouris, M. High-resolution spectral mapping of urban thermal properties with Unmanned Aerial Vehicles. Build. Environ. 2017, 121, 215-224. [CrossRef]

113. Baldinelli, G.; Bonafoni, S.; Anniballe, R.; Presciutti, A.; Gioli, B.; Magliulo, V. Spaceborne detection of roof and impervious surface albedo: Potentialities and comparison with airborne thermography measurements. Sol. Energy 2015, 113, 281-294. [CrossRef]

114. Ilehag, R.; Bulatov, D.; Helmholz, P.; Belton, D. Classification and representation of commonly used roofing material using multisensorial aerial data. Int. Arch. Photogramm. Remote Sens. Spat. Inf. Sci.-ISPRS Arch. 2018, 42, 217-224. [CrossRef]

115. Matias, M.; Lopes, A. Surface radiation balance of urban materials and their impact on air temperature of an Urban canyon in Lisbon, Portugal. Appl. Sci. 2020, 10, 2193. [CrossRef]

116. Feng, L.; Tian, H.; Qiao, Z.; Zhao, M.; Liu, Y. Detailed Variations in Urban Surface Temperatures Exploration Based on Unmanned Aerial Vehicle Thermography. IEEE J. Sel. Top. Appl. Earth Obs. Remote Sens. 2020, 13, 204-216. [CrossRef]

117. Honjo, T.; Tsunematsu, N.; Yokoyama, H.; Yamasaki, Y.; Umeki, K. Analysis of urban surface temperature change using structure-from-motion thermal mosaicing. Urban Clim. 2017, 20, 135-147. [CrossRef]

118. Chen, Y.C.; Chiu, H.W.; Su, Y.F.; Wu, Y.C.; Cheng, K.S. Does urbanization increase diurnal land surface temperature variation? Evidence and implications. Landsc. Urban Plan. 2017, 157, 247-258. [CrossRef]

119. Allinson, D.; Medjdoub, B.; Wilson, R. Toward quantitative aerial thermal infrared thermography for energy conservation in the built environment. Thermosense XXVII 2005, 5782, 133. [CrossRef]

120. Ham, Y.; Golparvar-Fard, M. Automated Cost Analysis of Energy Loss in Existing Buildings Through Thermographic Inspections and CFD Analysis. In Proceedings of the ISARC 2013-30th International Symposium on Automation and Robotics in Construction with 23rd World Mining Congress, Montreal, QC, Canada, 11-15 August 2013; pp. 1065-1073. [CrossRef]

121. Mandanici, E.; Conte, P. Aerial thermography for energy efficiency of buildings: The ChoT project. Remote Sens. Technol. Appl. Urban Environ. 2016, 10008, 1000808. [CrossRef]

122. Hu, Z.; Bai, Z.; Yang, Y.; Zheng, Z.; Bian, K.; Song, L. UAV Aided Aerial-Ground IoT for Air Quality Sensing in Smart City: Architecture, Technologies, and Implementation. IEEE Netw. 2019, 33, 14-22. [CrossRef]

123. Vo, T.D.H.; Lin, C.; Weng, C.E.; Yuan, C.S.; Lee, C.W.; Hung, C.H.; Bui, X.T.; Lo, K.C.; Lin, J.X. Vertical stratification of volatile organic compounds and their photochemical product formation potential in an industrial urban area. J. Environ. Manage. 2018, 217, 327-336. [CrossRef]

124. Liu, F.; Zheng, X.; Qian, H. Comparison of particle concentration vertical profiles between downtown and urban forest park in Nanjing (China). Atmos. Pollut. Res. 2018, 9, 829-839. [CrossRef]

125. Jensen, O.B. Drone city-Power, design and aerial mobility in the age of "smart cities". Geogr. Helv. 2016, 71, 67-75. [CrossRef]

126. Alsamhi, S.H.; Ma, O.; Ansari, M.S.; Almalki, F.A. Survey on collaborative smart drones and internet of things for improving smartness of smart cities. IEEE Access 2019, 7, 128125-128152. [CrossRef]

127. Park, K.; Ewing, R. The Usability of Unmanned Aerial Vehicles (UAVs) for Pedestrian Observation. J. Plan. Educ. Res. 2018. [CrossRef]

128. Perboli, G.; Rosano, M. Parcel delivery in urban areas: Opportunities and threats for the mix of traditional and green business models. Transp. Res. Part C Emerg. Technol. 2019, 99, 19-36. [CrossRef]

129. Park, J.Y.; Nagy, Z. Comprehensive analysis of the relationship between thermal comfort and building control research-A data-driven literature review. Renew. Sustain. Energy Rev. 2018, 82, 2664-2679. [CrossRef] 